Florida International University

FIU Digital Commons

\title{
The Relationship Between Educational Placement, Instructional Practices, and Achievement Gains of Black Students with Specific Learning Disabilities in Secondary Urban School Settings
}

Deidre Marshall Phillips

Florida International University, dtsp27@yahoo.com

DOI: $10.25148 /$ etd.FI12050130

Follow this and additional works at: https://digitalcommons.fiu.edu/etd

\section{Recommended Citation}

Phillips, Deidre Marshall, "The Relationship Between Educational Placement, Instructional Practices, and Achievement Gains of Black Students with Specific Learning Disabilities in Secondary Urban School Settings" (2012). FIU Electronic Theses and Dissertations. 593. https://digitalcommons.fiu.edu/etd/593 


\section{FLORIDA INTERNATIONAL UNIVERSITY \\ Miami, Florida}

\section{THE RELATIONSHIP BETWEEN EDUCATIONAL PLACEMENT, INSTRUCTIONAL PRACTICES, AND ACHIEVEMENT GAINS OF BLACK STUDENTS WITH SPECIFIC LEARNING DISABILITIES IN SECONDARY URBAN SCHOOL SETTINGS}

A dissertation submitted in partial fulfillment of the requirements for the degree of DOCTOR OF EDUCATION in EXCEPTIONAL STUDENT EDUCATION by

Deidre Marshall Phillips

2012 
To: Dean Delia C. Garcia

College of Education

This dissertation, written by Deidre Marshall Phillips, and entitled The Relationship Between Educational Placement, Instructional Practices, and Achievement Gains of Black Students with Specific Learning Disabilities in Secondary Urban School Settings, having been approved in respect to style and intellectual content, is referred to you for judgment.

We have read this dissertation and recommend that it be approved.

Patricia Barbetta

Monika Shealey

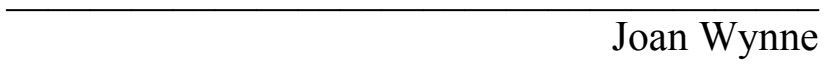

Elizabeth Cramer, Major Professor

Date of Defense: March 27, 2012

The dissertation of Deidre Marshall Phillips is approved.

Dean Delia C. Garcia

College of Education

Dean Lakshmi N. Reddi

University Graduate School

Florida International University, 2012 
(C) Copyright 2012 by Deidre Marshall Phillips

All rights reserved. 


\section{DEDICATION}

This dissertation is dedicated to our little girl on the way. The motivation and endurance I gained from you has sustained me throughout this process. You were a driving force in the completion of this monumental task. Thank you for showing me that my goals can be accomplished with dedication and perseverance. I also would like to express my sincere love and appreciation for my husband and parents whose prayers and encouragement pushed me along the way. Finally, thank you Lord Jesus for Your love, favor, and grace which has kept me and continues to sustain me even now. I love you all! 


\section{ACKNOWLEDGMENTS}

My sincere gratitude goes to the members of my committee who each played a significant role in my achievement because of their honesty, input, and support.. Thank you for taking the time required to provide thoughtful feedback which has made me a better writer and thinker.

I want to extend a special thank you to my major professor, Dr. Elizabeth Cramer, who was instrumental in my development as a doctoral student; her guidance was invaluable. This dissertation is a result of the academic and financial support from the Urban SEALS grant; thank you Dr. Patricia Barbetta and Dr. Elizabeth Cramer for making this possible.

I would also like to thank Dr. Isadore Newman and Dr. Linda Bliss for their academic advice, flexibility, and patience throughout the preparation of this dissertation. Additionally, a special thank you is extended to my Urban SEALS cohort for the support and assistance provided throughout my doctoral studies. I have grown, professionally and personally, through the friendships that were created along the way.

Finally, I would like to acknowledge my friends and family for your unending encouragement. Your faith in me bringing this to completion will not be forgotten. You are truly loved and appreciated. 


\author{
ABSTRACT OF THE DISSERTATION \\ THE RELATIONSHIP BETWEEN EDUCATIONAL PLACEMENT, \\ INSTRUCTIONAL PRACTICES, AND ACHIEVEMENT GAINS OF BLACK \\ STUDENTS WITH SPECIFIC LEARNING DISABILITIES IN SECONDARY URBAN \\ SCHOOL SETTINGS \\ by \\ Deidre Marshall Phillips
} Florida International University, 2012 Miami, Florida Professor Elizabeth Cramer, Major Professor

Black students, in general, are underserved academically (Darling-Hammond, 2000; Townsend, 2002) and overrepresented in special education (Donovan \& Cross, 2002). Black students with disabilities are further overrepresented in more restrictive educational environments (Skiba, Poloni-Staudinger, Gallini, Simmons \& Feggins-Azziz, 2006). Although the National Longitudinal Transition Study 2 (NLTS2) revealed that the academic performance of students with learning disabilities is positively related to the percentage of courses taken in the general education setting (Newman, 2006), the research specifically on placement of Black students with disabilities, particularly at the secondary level, as it relates to academic achievement is lacking. While previous studies have sought to determine which placement is better for students with disabilities, no study was found that specifically examined the impact of placement specific to Black students with specific learning disabilities (SLD) in urban settings (Fore, III, HaganBurke, Burke, Boon \& Smith, 2008; Rea, McLaughlin \& Walther-Thomas, 2002). 
This study examined educational placement, instructional best practices, and achievement gains of Black students with SLD in urban secondary settings using an ex post facto research design. Achievement, placement, and demographic data were collected and analyzed on approximately 314 Black eighth grade students with SLD. The Teacher Instructional Practices Survey was developed and used to collect and analyze data from the teachers of 78 of these students as it relates to instructional best practices. Results indicate no significant difference in reading but a significant difference in math gains of students served in inclusive settings as compared to resource settings with a small effect size. Also, no significant relationship was found between achievement gains and the reported use of instructional best practices. However, there was a relationship between educational placement and the use of instructional best practices. The results implied that there is a need for training with both general and special education teachers on instructional best practices for SWD and that there should be certain IEP team considerations when making placement decisions for this population of students with disabilities. It is recommended that future research in this area include classroom observations and factors other than test scores to measure growth in achievement. 


\section{TABLE OF CONTENTS}

CHAPTER

PAGE

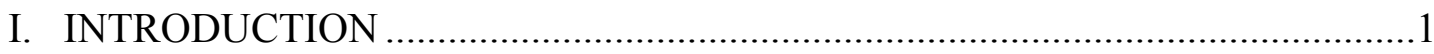

Purpose of the Study ……........................................................................

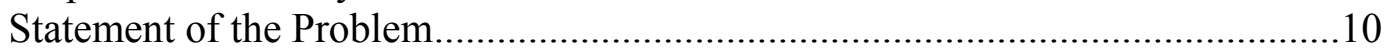

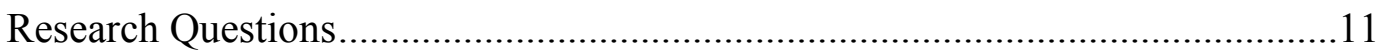

Definition of Important Terms and Concepts ......................................................11

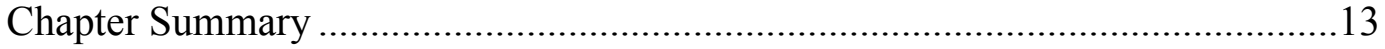

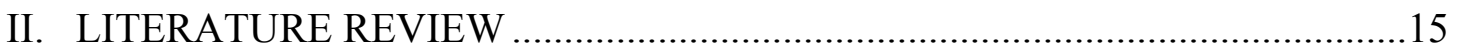

Black Students and Academic Achievement in Secondary Settings.....................15

Black Students in Urban Special Education........................................................21

Instructional Best Practices for Secondary Students With Disabilities.................23

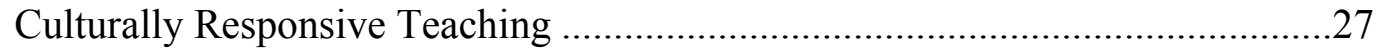

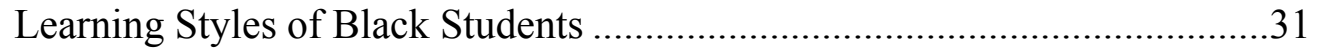

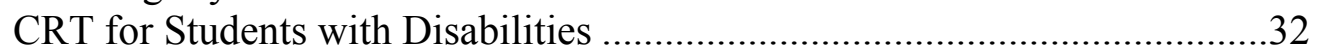

Educational Placement of Secondary Students With Disabilities ...........................34

Chapter Summary ……............................................................................... 40

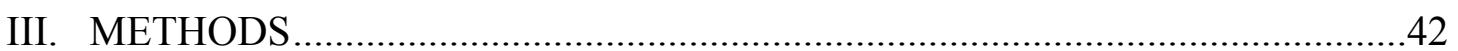

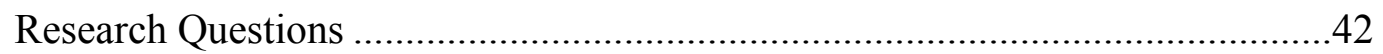

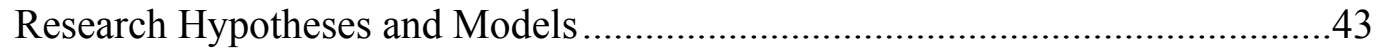

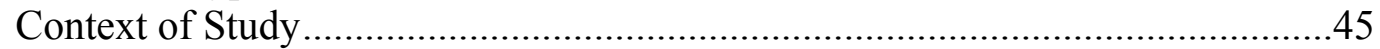

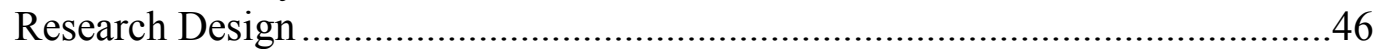

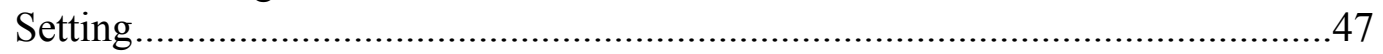

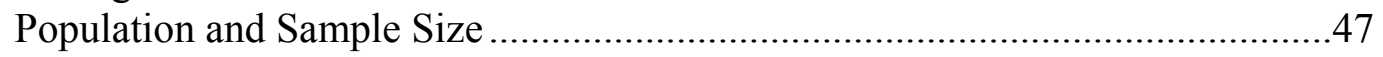

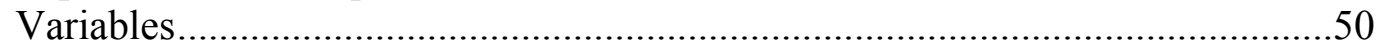

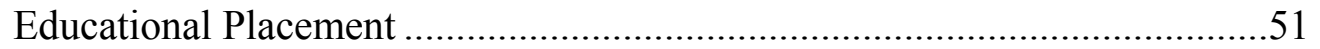

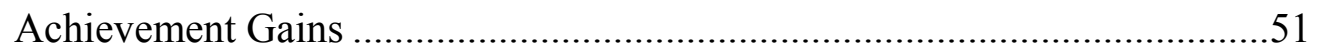

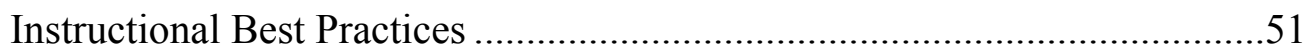

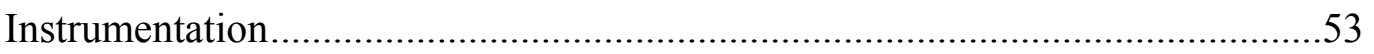

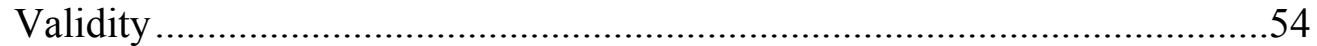

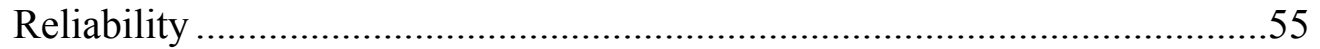

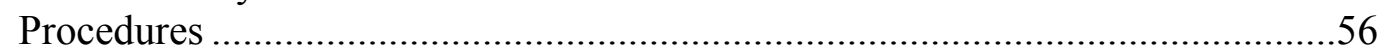

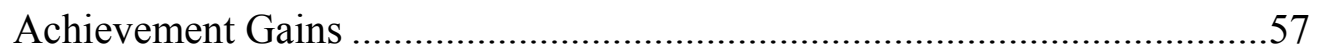

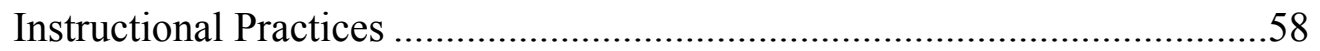

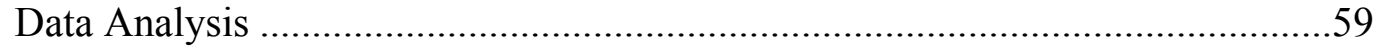

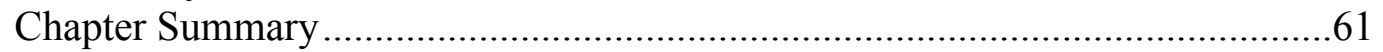

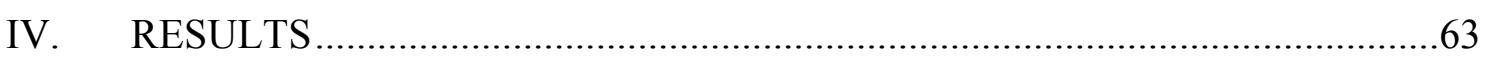

Student Demographic Descriptive Statistics ......................................................63

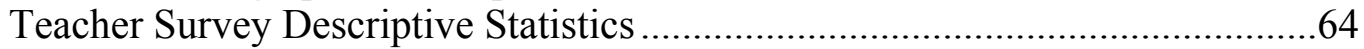


Open-Ended Survey Items............................................................................66

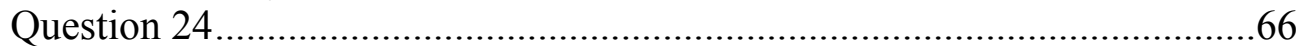

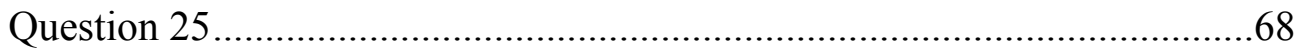

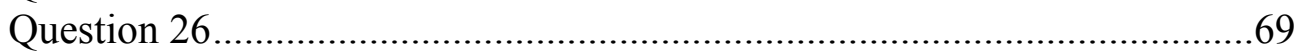

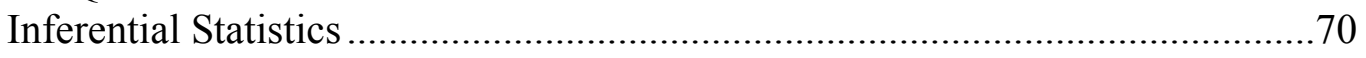

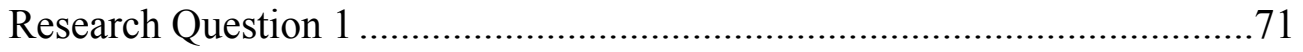

Research Question 2 ............................................................................

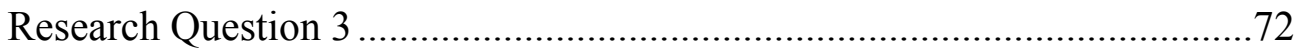

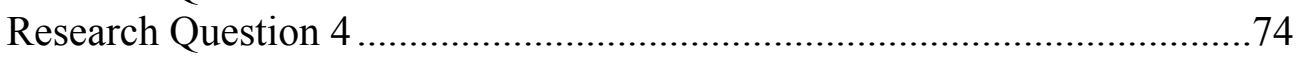

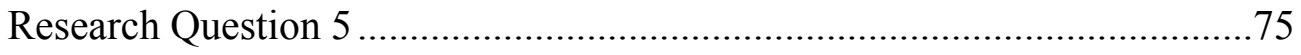

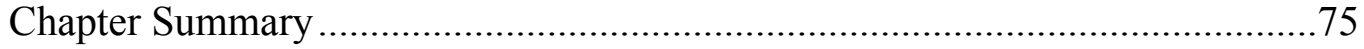

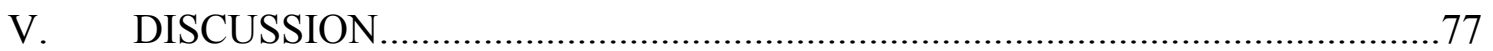

Achievement Gains and Educational Placement ..............................................79

Educational Placement and Instructional Best Practices....................................80

Achievement Gains and Instructional Best Practices ..........................................81

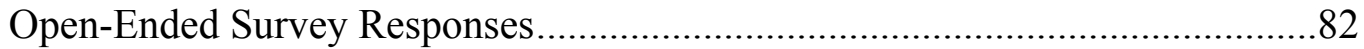

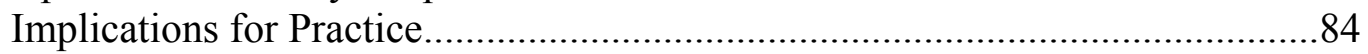

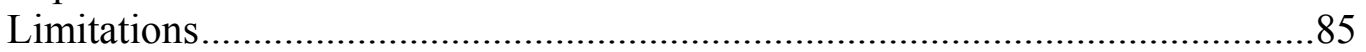

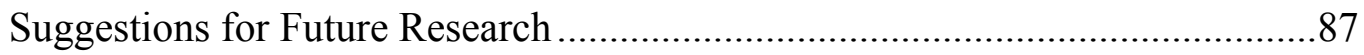

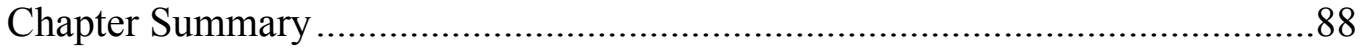

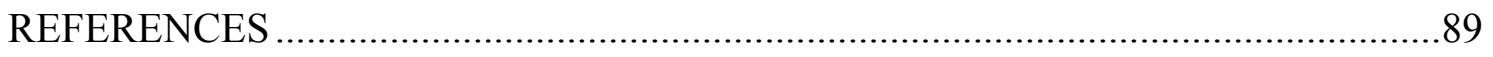

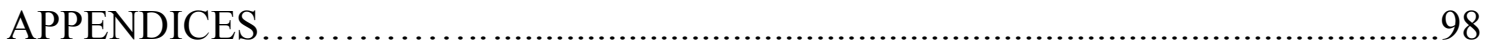

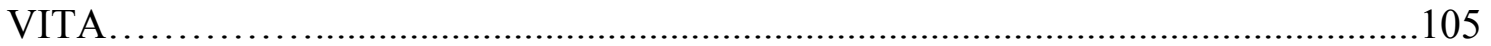




\section{LIST OF TABLES}

TABLE

PAGE

1. Student Demographic Frequencies Table ……………............................................. 48

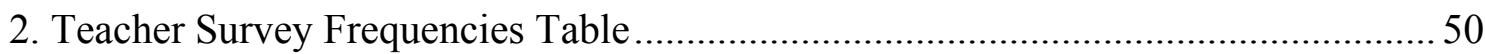

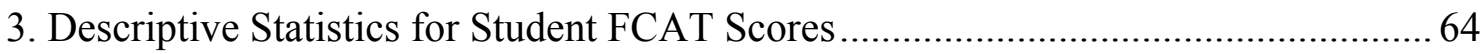

4. Descriptive Statistics for Instructional Best Practices: Reading..................................65

5. Descriptive Statistics for Instructional Best Practices: Math....................................... 65

6. Question 24: Additional Instructional Practices in Reading........................................... 67

7. Question 24: Additional Instructional Practices in Math.............................................67

8. Question 25: Most Effective Practice for SWD in Reading ........................................ 68

9. Question 25: Most Effective Practice for SWD in Math ............................................... 69

10. Question 26: Additional Information in Reading ................................................ 70

11. Question 26: Additional Information in Math ..................................................... 70

12. Model Summary of Educational Placement and Math Gains .................................... 71

13. Coefficients: Educational Placement and Math Gains............................................. 71

14. Model Summary of Educational Placement and Reading Gains ............................ 72

15. Educational Placement and Instructional Best Practices: Reading ........................... 73

16. Educational Placement and Instructional Best Practices: Math ................................ 74

17. Model Summary of Instructional Best Practices and Reading Gains ....................... 75

18. Model Summary of Instructional Best Practices and Math Gains ............................ 75 


\section{Chapter I}

\section{INTRODUCTION}

Black students have long been documented for overrepresentation in special education (Artiles \& Trent, 1994; Brosnan, 1983; Ferri \& Connor, 2005; Patton, 1998). Overrepresentation occurs when the percentage of students within an ethnic/racial group is greater than the percentage of that group in the general population (National Association for Bilingual Education [NABE], 2002). Overrepresentation is the practice of identifying students from a specific ethnic or racial group for special education services in disproportionately large numbers (Donovan \& Cross, 2002).

Although Black students make up 15.3\% of the total population of students enrolled in public schools, approximately $20 \%$ are receiving services under IDEA, the Individuals with Disabilities Education Improvement Act (Planty et al., 2009). With a risk index of 14.28\% (Harry \& Klinger, 2006), the percentage of Black students at risk of receiving a disability label is higher for ethnic disproportionality in intellectual disabilities, specific learning disabilities, and emotional disturbances; whereas White students carry a risk index of $12.10 \%$ (Donovan \& Cross, 2002). The risk index, also known as risk ratio, is the possibility that a particular group of students will be newly identified as students with a disability when compared to all others.

Blacks in the United States continue to encounter educational deficits at a high rate due to unequally structured learning opportunities (Darling-Hammond, 2000; Townsend, 2002). Several key findings of the Racial Justice Report Card (Gordon, Piana, \& Keleher, 2000) revealed a prevalence of statistical data pointing to racial inequalities and discrimination in U.S. public schools and a higher drop out and/or "pushed out of 
school" rate for students of color. Black and Latino students are also overrepresented in remedial and vocational tracks. Cases in point, ethnically diverse students with disabilities, including Blacks, are often excluded from the general education classroom (Reid \& Knight, 2006). Even with the push for more inclusive practices from the national and state level (Individuals with Disabilities Education Improvement Act of 2004 [IDEA], 2004; No Child Left Behind Act of 2001 [NCLB], 2002), the presence of Black students with disabilities included in the general education setting does not guarantee educational equity (Townsend, 2002).

Hayes and Price (2000) asserted that the special education process starts on the very first day of school and continues to reign as an alternative to regular education for Black students, particularly males. The general classroom typically presents an unusual method of learning and behavior for Black, male students that leads to the cycle of low expectations, low self-esteem, and inappropriate curriculum and teaching methods making learning difficulties appear endemic. Even within the general education setting, poor urban children spend significantly less time directly engaged in academic learning than do their suburban counterparts (Hayes \& Price, 2000). There is also evidence of contrasting outcomes for students of color and White students who are labeled disabled. Students of color with an identified disability are subjected to poorer transition outcomes and have less access to general education than White students found eligible for special education who are more likely to have maintenance in general education settings, access to extra support services, and high-stakes testing accommodations. This is especially problematic given that Black students are disproportionately identified as disabled (Ferri \& Connor, 2005). 
Brayboy, Castagno, and Maughan (2007) examined recent research on race in education and found that equality by itself may not be able to overcome the long influential history of structural racism on American schools and racialized communities. In essence, equality or sameness does not create equity. Reid and Knight (2006) have argued that the principles of "normalcy" create disadvantaged systems of education for ethnically diverse students because they naturally allow for students of color to be seen as "other" by associating them with a disability. Historically, marginalization and exclusion of minority students has been justified by an overlap in the rhetoric of race and disability. The demographics of specific learning disability (SLD) programs have shifted from primarily White students to students of color and students with SLD in urban settings are more likely to be serviced in more restrictive environments than their suburban peers. This suggests that the amount of time a student with a disability spends in the general education setting is highly correlated to the student's race (Ferri \& Connor, 2005). Schools are now held accountable for the academic achievement of students with disabilities gained through access to the general education curriculum.

Accountability systems launched in the 1990s had a positive influence on state achievement growth as measured by the National Assessment of Educational Progress (Hanushek \& Raymond, 2005). NCLB requires states to report the math and reading testscore results to determine if schools are making adequate progress towards having all students proficient in both areas by 2014. Schools must meet a steadily increasing targeted percentage of proficient students statewide to make adequate yearly progress (AYP). The same targets must be met by different subgroups within each school based on disability, income, ethnicity, and English-language-learner status. Yet for the 2010-2011 
school year, only $56 \%$ of the AYP criteria was met by Florida schools (Florida Department of Education [FLDOE], 2011b). Therefore, the state did not make adequate yearly progress.

Access to the general education curriculum coupled with the competence of educators to teach diverse learners are both key factors in the success of students with disabilities according to school reform mandates (Nagle, Yunker, \& Malmgren, 2006). As Karger (2005) explains it, IDEA requires access to the general education curriculum so that students with disabilities can meet the standards applicable to all children, while NCLB helps to define and raise the level of the general education curriculum (inclusive of students with disabilities). Both NCLB and IDEA have high expectations for the academic performance of students with disabilities.

IDEA (2004) mandates both a free and appropriate public education (FAPE) within the least restrictive environment (LRE) and access to the general curriculum for students with disabilities. The general curriculum is defined as the same curriculum and standards based instruction that nondisabled peers receive. The purpose of this mandate is to ensure that students with disabilities have access to a demanding curriculum, are held to high expectations, and are not excluded from accountability measures stemming from school reform (Wehmeyer, Lattin, Lapp-Rincker, \& Agran, 2003). This requires that students' Individual Education Plans (IEP) address the accommodations and modifications that will be used to guarantee involvement and progress (defined by content and student performance standards) in the general education curriculum. However, IEPs, which document the specialized services students with disabilities 
receive, often lack a relationship to the general curriculum or are rarely used as guidelines for standard instruction (Karger, 2004).

To help teachers determine the best setting to access the general curriculum, King-Sears (2001) presented a three-step process to examine and assess the aspects of the general curriculum that impede or increase success for students with mild to moderate disabilities. The three steps in order are: (a) evaluate the general education curriculum, (b) improve the poorly designed areas of the curriculum, and (c) consider creative ways for students to access the curriculum that includes modification of outcomes. The author believes that teachers who complete this process not only make placement decisions that are more individualized and methodical, but they also increase learning for students with mild to moderate disabilities as well as typical and at-risk students. Unfortunately, there are no clear policies on how to promote "access" to the general education curriculum, which has led to different definitions of exactly what it means to do so. Access without a clear definition is often viewed as simply physically placing a student with a disability into a general education classroom and is not seen as providing the supports needed to ensure academic performance and progress within the curriculum; the original intent of the IDEA mandate (Soukup, Wehmeyer, Bashinski, \& Bovaird, 2007). IDEA specifically states the following

To the maximum extent appropriate, children with disabilities, including children in public or private institutions or other care facilities, are educated with children who are not disabled, and that special classes, separate schooling, or other removal of children with disabilities from the regular educational environment occurs only when the nature or severity of the disability is such that education in 
regular classes with the use of supplementary aids and services cannot be achieved satisfactorily. (IDEA, 2004, 20 U.S.C. 1412 (5) (B)) When determining the least restrictive environment, a full continuum of services must be available and access to FAPE must be considered. Additionally, the law requires that all placement decisions be made on an individual basis (Hagan-Burke \& Jefferson, 2002). Regardless of the regulation of federal laws, determining appropriate placement for students with disabilities proves to be a complicated issue (Yell \& Katsiyannis, 2004).

The field of special education continues the debate on how or where schools can best educate students with disabilities. Research on the effectiveness of general education placement versus the resource setting both support and oppose the traditional separate model. Failing to focus on instruction as a method of enhancing the education of students with disabilities has brought criticism to special education reform movements that influence school practices regarding placement decisions (Hagan-Burke \& Jefferson, 2002; Kauffman, 1996; Zigmond, 2003). With "educational benefit" as the standard for responsible inclusion, the primary focus should be placement for instruction rather than the mere physical location of the instruction. This suggests that data, not philosophy, should guide IEP decisions regarding placement in the least restrictive environment (Hagan-Burke \& Jefferson, 2002). Rueda, Gallego, and Moll (2000) add to this concept by offering an expanded view of LRE. Using a sociocultural framework, the authors also argue that the physical context should not be the focus of LRE. Instead, they suggest that the same setting/placement can be either restrictive or facilitating depending on the social organization that comprises a given context and the related specific activity settings within that context. IEP teams should not make placement decisions based on severity of 
disability, disability label, availability of educational or related services within a particular setting, availability of space, or administrative suitability; all are illegitimate reasons for choosing placement (Yell \& Katsiyannis, 2004).

While previous studies have sought to determine which placement is better for students with disabilities (Cawley, Hayden, Cade, \& Baker-Kroczynski, 2002; Fore, III, Hagan-Burke, Burke, Boon \& Smith, 2008), none of the studies located have specifically examined the impact of placement specific to Black students with disabilities in urban settings. In 2002, Rea, McLaughlin, and Walther-Thomas studied the relationship between inclusive and pull-out special education programs for students with learning disabilities as it related to academic and behavioral outcomes. Although the results indicated that students served in inclusive settings earned higher grades, had higher school attendance, committed no more behavioral infractions, and achieved higher or comparable scores on standardized tests than students serviced in the pullout setting, that study did not include Black students with disabilities nor did it examine urban settings. The archival qualitative data used in the study were not observable by the researchers to verify the degree of accommodations described in the findings. Furthermore, the study took place in a southeast suburban school district with approximately $76 \%$ of the participants identified as Caucasian. The remaining participants were simply identified as non-white.

\section{Purpose of the Study}

There are two key concepts at the center of IDEA (2004) and its regulations intended to encourage improved outcomes for students with disabilities: access to the general curriculum and participation in standardized assessments. Students with 
disabilities are now being held to the same standards as their non-disabled peers. This involves providing students with the opportunity to achieve high standards, the same standards that form the basic foundation of the general curriculum and accountability assessments, and the teachers' role of helping students access the curriculum and supporting student participation in assessments (Access Center, n.d.). Simply placing students with disabilities in general education classrooms is not enough. Karger and Hitchcock (2003) explain that successful inclusion requires participation and progress in the same meaningful curriculum and content standards that students without disabilities receive. It also means that students with disabilities are "provided with the supports necessary to allow them to benefit from instruction" (Nolet \& McLaughlin, 2000, p. 9), which would include effective instructional practices. It is reported that the majority of students with learning disabilities in secondary schools spend at least part of their day in a general education setting (Newman, 2006).

Black students, in general, are underserved academically (Darling-Hammond, 2000; Townsend, 2002) and overrepresented in special education (Donovan \& Cross, 2002). Black students with disabilities are further overrepresented in more restrictive educational environments (Skiba, Poloni-Staudinger, Gallini, Simmons \& Feggins-Azziz, 2006). In other words, even within special education, Black students with disabilities are more likely to be served in separate settings. Still, the presence of these students in the general education classroom does not guarantee educational equity (Townsend, 2002). Although the National Longitudinal Transition Study 2 (NLTS2) revealed that the academic performance of students with learning disabilities is related to the percentage of courses taken in the general education setting (Newman, 2006), the research on 
placement of Black students with disabilities, particularly at the secondary level, as it relates to academic achievement is lacking. This, along with the fact that Black students are academically underserved and overrepresented in special education, demonstrated a need to examine the educational placement and achievement of secondary Black students with disabilities.

The purpose of this study was to compare inclusive and resource educational placement, including the use of best practices, and the academic achievement of Black students with disabilities, particularly in urban secondary settings. Secondary settings were chosen because inclusive education is a challenge at the middle, junior high, and high school levels (Kozik, Cooney, Vinciguerra, Gradel, \& Black, 2009). Although the term African American is often used in the literature, Black is the term used in this study to encompass the mixture of Haitian, Jamaican, and African American students with disabilities in south Florida. This study sought to determine whether Black students with specific learning disabilities in urban secondary school settings serviced in inclusive content area courses demonstrate a difference in achievement gains as evidenced by growth in developmental scale scores when compared to urban secondary Black students with specific learning disabilities serviced in resource settings. Achievement gains, or gain scores, are measured by subtracting the 2010 FCAT scale score from the 2011 FCAT scale score in both math and reading. In addition, this study sought to determine if the reported use of instructional best practices is a predicting factor of achievement gains with this population of students. 


\section{Statement of the Problem}

Although research on educational placement for students with disabilities exists, it is not specific to large schools that primarily service Black students with disabilitiesespecially in secondary settings. Additionally, the research reviewed did not examine the instructional practices of each classroom setting within urban schools. Low achieving minority students are typically placed in class structures not conducive to their success. School reform measures have added pressure to provide equitable and quality educational programs for minority learners with disabilities. As Obiakor and Utley (2004) describe it, "misidentification leads to misassessment, misassessment leads to miscategorization, miscategorization leads to misplacement, and misplacement leads to misinstructionmisintervention" (p. 150). If Black students with disabilities are not showing growth in achievement, then it may warrant an examination of their educational placement as well as the instructional practices within that environment.

The exaggerated number of Blacks disproportionately represented in special education coupled with the fact that poor urban children are less engaged academically when compared to their suburban peers calls for an in depth look into the educational placement of Black students with disabilities; that is, their placement for accessing the general curriculum and the corresponding academic achievement within that placement. It is imperative that classroom placement and instructional practices are examined to determine if they are academically beneficial for Black students serviced in educational programs where they are generally overrepresented. 


\section{Research Questions}

This study was based on the hypothesis that there is a significant difference between the academic achievement gains of Black students with specific learning disabilities serviced in inclusive class placements as compared to Black students with specific learning disabilities serviced in resource class placements. This study also hypothesized that there is a relationship between the achievement gains of Black students with specific learning disabilities and the reported use of instructional best practices in each educational placement. This study investigated the following research questions:

1. Is there a significant difference in math achievement gains of Black students with SLD serviced in secondary resource settings as compared to inclusive educational classroom placements?

2. Is there a significant difference in reading achievement gains of Black students with SLD serviced in secondary resource settings as compared to inclusive educational classroom placements?

3. What is the relationship between the educational placement of Black students with SLD and the reported use of instructional best practices?

4. Is there a relationship between the reading achievement gains of Black students with SLD and the reported use of instructional best practices?

5. Is there a relationship between the math achievement gains of Black students with SLD and the reported use of instructional best practices?

\section{Definition of Important Terms and Concepts}

The following terms and concepts are defined below for the purposes of this study: 


\section{Florida Comprehensive Assessment Test ${ }^{\circledR}$ (FCAT)}

A test that measures student performance on selected benchmarks in reading, mathematics, writing, and science that are defined by the Florida Sunshine State Standards (SSS).

\section{Instructional Best Practices}

Effective instructional practices as evidenced through research (Cook, Tankersley, \& Landrum, 2009). The instructional best practices identified for the purpose of this study were found in the literature to be effective for secondary students with disabilities across subject areas as measured by the Teacher Instructional Practices Survey (see Appendix A).

\section{Inclusive Setting}

A less restrictive classroom setting that educates both general and special education students using grade level standard curriculum and is typically taught by a general education teacher with the support of the special educator; student records indicated classroom setting.

\section{Resource Setting}

A more restrictive classroom setting taught by special educators that serves special education students and uses grade level curriculum; student records indicated classroom setting.

\section{Scale Scores}

The score used to report test results on the entire FCAT SSS test. Scale scores range from 100 to 500 for each grade level and content area. 


\section{Specific Learning Disability}

A disorder in one or more of the basic psychological processes involved in understanding or in using language, spoken or written. The disorder may manifest itself in an imperfect ability to listen, think, speak, read, write, spell or do mathematical calculations. Student records established whether or not this disability exists when identifying participants.

\section{Chapter Summary}

Blacks continue to not only be overrepresented in special education (Donovan \& Cross, 2002; Harry \& Klingner, 2006), but also experience educational deficits at a high rate (Townsend, 2002). Within special education programs, Blacks are more likely to be serviced in more restrictive environments (Ferri \& Connor, 2005). With the launch of federal and state accountability systems and the push for schools to provide the least restrictive environment, inclusive education has been emphasized as a service delivery model for students with disabilities.

With the IDEA mandate that students access the general education curriculum, schools are providing more opportunities for inclusive practices. However, the research is divided on where schools can best educate students with disabilities (Hagan-Burke \& Jefferson, 2002). Furthermore, the research on placement of Black students with disabilities, particularly at the secondary level, as it relates to academic achievement was lacking. This demonstrated a need to examine placement and achievement of secondary Black students with disabilities. 
This study examined the relationship between inclusive and resource educational placement, instructional practices, and academic achievement of Black students with specific learning disabilities. In addition, this study investigated whether Black students with specific learning disabilities serviced in inclusive content area courses demonstrated a difference in achievement gains when compared to those serviced in resource settings and the relationship to the reported use of instructional best practices. 


\section{Chapter II}

\section{LITERATURE REVIEW}

This chapter is divided into five main sections: Black students and academic achievement in secondary settings, Black students in urban special education, instructional "best" practices for secondary students with disabilities, culturally responsive teaching, and educational placement of secondary students with disabilities. The purpose of this study was to compare inclusive and resource educational placement and the academic achievement of Black students with disabilities in conjunction with the reported use of instructional best practices in each placement. This research sought to determine whether Black students with disabilities in urban secondary school settings serviced in inclusive content area courses had higher achievement gains in comparison to Black students with disabilities serviced in resource settings. Additionally, this study explored the relationship of instructional best practices to the educational placement and achievement gains of this population of students.

\section{Black Students and Academic Achievement in Secondary Settings}

As evidenced by research, Black students are generally underserved academically (Darling-Hammond, 2000; Townsend, 2002). To further complicate the issue, Kellow and Jones (2008) suggest that when their knowledge and skills are measured using a high-stakes standardized test, Black students are at a disadvantage compared to White students. Kellow and Jones (2008) made this conclusion following their investigation on whether Black high school freshman students experienced stereotype threat when taking a test that is seen as a predictor of their success on a high-stakes test. The researchers conceptually replicated a previous study using a true experimental design and found that 
White students scored significantly higher than Black students when told that their test performance would be predictive of their performance on a statewide, high-stakes standardized test. Potential mediators of stereotype threat include: perceptions of ability and expectancy for success, achievement of goal orientation, anxiety, and perceptions of stereotype threat.

When it comes to standardized testing, the nation's states and school districts have been criticized (Peterson \& West, 2006) and praised (Hanushek \& Raymond, 2005) for the accountability systems developed to improve student achievement. Fuller and Johnson, Jr. (2001) analyzed the impact of accountability systems on student achievement of children from low-income households and children of color by examining the extent to which the Texas school accountability system may have driven progress in school performance for children of color and those from low-income homes.

Disaggregated student achievement data from the state education agency proved that Blacks passing the Texas Assessment of Academic Skills demonstrated a gain of 22 points in reading, 19 points in writing, and 40 points in math from 1994 to 2000 . There was a $423.3 \%$ increase of Black students taking at least one advanced-placement exam from 1992 to 2000. Although student improvement in school performance was evident, a causal relationship between accountability systems and improved student achievement was not determined.

Although accountability measures may have led to some improvements for Black students, ethnic differences between groups still exist. Byrnes (2003) identified six explanations for ethnic differences in mathematics achievement: (a) unequal access to quality schools, (b) within-school bias in the assignment of students to academic tracks, 
(c) ethnic differences in elective coursework, (d) within-classroom disconnects between teacher and students, (e) differences due to home environments, and (f) differences due to ethnic differences in aptitude or expertise. This study used a secondary analysis of the National Assessment of Educational Progress to offer insight into the ethnic differences in 12th grade math achievement. The three conditions (3C) model of achievement, designed to integrate and extend explanations of ethnic differences, was used as a guide. Results of the regression analysis showed that ethnicity accounts for less than $5 \%$ of the variance in math. In contrast, the following variables central to the $3 \mathrm{C}$ model accounted for $45 \%-50 \%$ of the variance: socioeconomic status indicators, exposure to learning opportunities, and motivational aspects of math. This implies great prospects in closing the achievement gap when addressing ethnic differences.

Berry (2003) hypothesizes that Black students not only receive math instruction that is in opposition to their cultural framework and learning preference, but they also receive math instruction that is inconsistent with mathematics education reform. In the article, Berry summarizes the mathematics National Assessment of Educational Progress (NAEP) literature on assessment as it relates to eighth-grade Black students and describes the learning preferences and cultural styles of these students. A comparison is made between the National Council of Teachers of Mathematics (NCTM) Process standards and the cultural styles and learning preferences described for Black students. The findings suggest that a positive influence on math achievement of Black students is possible when math instruction is based on the NCTM standards; such instruction goes hand in hand with their learning styles and cultural preferences. 
To promote achievement in this era of accountability, Sheppard (2006) sought to determine the reasons why successful mathematics students have been able to thrive in schools labeled academically unacceptable and why they have chosen to stay in these schools despite having the option to leave. Using qualitative methods including group interviews, individual interviews, and open-ended questionnaires, the author found that students attribute their success in math to good teachers and personal character traits. Participants chose not to attend better performing schools because they felt comfortable and have developed a degree of trust at their current school. Moreover, the participants believed that graduating from a school with problems such as those associated with academically unacceptable schools would better prepare them for the "real world."

Pressley, Raphael, and Gallagher (2004) also found ways to promote achievement by using grounded theory to construct a portrait of a K-12 school serving urban, Black students producing high achievement. Observations complemented by questionnaire responses and document analyses were the primary means of data collection. The theory emerging from this research was that high achievement in this school was caused by multiple factors, including decidedly psychological ones. These consist of strong leadership, accountability, academic focus, orderliness, and others consistent with aspects of teaching and learning emphasized in the educational psychology literature.

In a similar investigation, Stewart (2007) examined the extent to which individual-level and school structural variables predict academic achievement among a sample of 10th grade Black students abstracted from the National Educational Longitudinal Study (NELS) database. This was done using regression-based techniques that account for within-school clustering of students. The results suggest individual-level 
predictors such as student effort, parent-child discussion, and associations with positive peers play a substantial role in increasing students' achievement. Results also suggest that school climate is important to successful student outcomes.

A narrative synthesis was conducted to address what research-based programs that balance academic attainment and achievement would look like when employed in middle and high schools serving students of color (Mayer \& Tucker, 2010). The five key strategies found to promote high achievement are (a) close monitoring of students' social and academic growth, (b) access to high-quality curriculum, (c) appropriate scaffolding, (d) academically supportive peer groups, and (e) opportunities for socioemotional growth. Researchers specify that the findings have the most impact on achievement when students are exposed to the strategies over a period of several years and when the strategies are implemented simultaneously.

Equally important is the link between academic achievement of Black high school students and school size. Slate and Jones (2006) examined this association by using data from the Texas Academic Excellence Indicator system for 1998-2000. The sample included approximately $65 \%$ of all Texas high schools with a grade 9 to 12 configuration. School size was based on student enrollment; achievement indicators included scores on the Texas Assessment of Academic Skills, SAT I, and ACT as well as final exams in Algebra I, English II, Biology, and U.S. History. Data were analyzed separately for each year and although they revealed greater achievement for Black students attending large schools (1200 or more students), the overall level of academic achievement was "unacceptably low." These findings imply that schools, regardless of size, continue to under serve Black students. 
Just as Slate and Jones examined Black achievement through school size, Ross, Seaborn, and Wilson (2002) examined Black achievement through instructional methods. They investigated whether there was a difference in the level of academic achievement for Black students when instructed through lecture and discussion versus cooperative learning methods in the social studies classroom. Participants were 58 Black 12th graders in an urban public school. A control group was instructed using traditional lecture and discussion, while an intervention group received instruction through the jigsaw method of cooperative learning. Data were also collected through student surveys and teacher interviews. Students' academic achievement levels were assessed using a pretest-posttest evaluation. Results indicated that there was no significant difference in academic achievement levels between students taught using cooperative learning and students taught using lecture and discussion.

In summary, the academic achievement of Black students is important to this study because it paints an academic picture for this population of students at the secondary level. The literature review in this area reveals that school climate and individual-level predictors, as well as accountability and good teachers, have played positive roles in increasing achievement with this population of students. In addition, regardless of size, schools continue to under serve Black students academically. The literature also shows that Black students are at a disadvantage when their achievement is measured using a high-stakes standardized test. Additionally, the literature review provided explanations into the ethnic differences in the math achievement of secondary students. The findings on secondary Black students and achievement are essential to the subgroup of secondary Black students with disabilities being examined in this study. 


\section{Black Students in Urban Special Education}

Of all the public school students in the United States, more than a third attend school in urban settings. Urban education has been defined as "those schools and systems that provide schooling for students in inner-corridor, densely populated, communities in which vast disparities in commerce, population density, transportation, socioeconomic status, and sociocultural backgrounds characterize the lives of people who live there" (Kozleski \& Smith, 2009, p. 428). Students that attend urban schools as well as those that are placed in special education share a history laced with undereducation, miseducation, and inequitable treatment by the U.S. education system. Students of color, students with disabilities, and poor schools in urban settings have also experienced a common struggle when it comes to receiving quality instruction (Blanchett, 2009; Blanchett, Klingner, \& Harry, 2009). Blacks and other students of color labeled as having a disability often experience double jeopardy: in addition to the experiences associated with attending urban schools and living in poverty, these students also experience the inequalities of the special education system (Blanchett et al., 2009).

The Supreme Court's landmark decision in the 1954 Brown v. Board of Education case not only mandated the desegregation of schools but also laid the foundation for challenging the segregation of students with disabilities, eventually leading to the passage of IDEA. However, there has not been an equal distribution of the special education benefits under IDEA and segregation on the basis of race, social class (Losen \& Orfield, 2002) and disability continues in special education programs as evidenced by disproportionality (Blanchett, Mumford, \& Beachum, 2005). Furthermore, Black students with disabilities are more likely to receive one of the disciplinary provisions of IDEA, 
with the most racial disparities found in the provision other suspension/expulsion greater than 10 days (Skiba et al., 2008).

Overall, more students with disabilities in general are being serviced in the general education setting. During the 1996-1997 academic year, 24 states reported that more than $50 \%$ of their students with learning disabilities were served in general education as compared to 33 states reporting the same during the 2006-2007 academic year (Kozleski \& Smith, 2009). However, this is not the case for Black students with disabilities. The concern with placing Black students with disabilities in more restrictive, segregated settings instead of more inclusive, general education classrooms is often cited by researchers. Black students with disabilities are more likely to be underrepresented in general education settings and overrepresented in more restrictive settings (Blanchett, 2009; Skiba et al., 2006), regardless of gender or type of disability (LeRoy \& Kulik, 2001). The U.S. Department of Education (2005) revealed that only $38.6 \%$ of black students with disabilities spent most of their school day in the regular classroom in comparison to $54.7 \%$ of White students.

In addition, Black students with disabilities are more likely to be taught by teachers without certification and to graduate with a special diploma. They also experience difficulties with accessing postsecondary education as well as high unemployment rates (Blanchett et al., 2009). For the targeted group of Black students in this study, examining the research regarding instructional best practices for students with disabilities is essential to understanding the achievement of Black students in urban special education. 


\section{Instructional Best Practices for Secondary Students with Disabilities}

Given the daunting task of providing meaningful access to the general education curriculum for adolescents with learning disabilities, it seems imperative that general and special secondary teachers are aware of the empirically validated or supported practices that promote academic success in middle and high schools. (Hughes, Maccini \& Gagnon, 2003, p. 101)

A review of the literature identifying and examining academic interventions for secondary students with learning disabilities from 1986 to 2002 found the following strategies to be the most effective practices that can be applied to various subject areas: (a) graphic organizers, (b) mnemonic instruction, (c) classwide peer tutoring, (d) guided notes, (e) coached elaboration (teacher questioning), and (f) inquiry teaching (activitiesbased, investigations) (Anderson, Yilmaz, \& Wasburn-Moses, 2004). The authors employed a narrative synthesis methodology to intervention research conducted with middle and high school students with learning disabilities. Various strategies were used to locate appropriate articles using a hand search of relevant journals and a computerized search through ERIC using key words. The articles that were included all met the following criteria: (a) empirical in nature; (b) participants from $6^{\text {th }}$ through $12^{\text {th }}$ grade; (c) participants were learning disabled; (d) effectiveness of a particular intervention was investigated; (e) generalization of intervention across subject areas.

In a similar study, Hughes, Maccini, and Gagnon (2003), reviewed the literature from 1970 to 2002 in search of interventions proven to positively affect the academic performance of students with learning disabilities in secondary general education classes.

The 35 articles that met criteria all targeted $6^{\text {th }}-12^{\text {th }}$ grade students with learning 
disabilities currently enrolled in general education classrooms and measured an interventions' impact on an academic task required in one or more general education classrooms.

Their findings are organized into three categories: student-focused, teacherfocused, and peer-focused. The student-focused interventions include learning strategies instruction and self-management procedures. Utilizing advance organizers, study guides, mnemonic enhancements, and graphic organizers are included as teacher-focused interventions. Peer tutoring was identified as the peer-focused intervention. The article also states that these interventions are effective for all students in general education and don't water-down content. In addition, the authors explain that a variety of approaches are necessary for student excess; no isolated intervention is adequate for academic growth (Hughes, Maccini \& Gagnon, 2003).

Maccini, Gagnon, and Hughes (2002) also reviewed the literature on technologybased practices for secondary students with learning disabilities. There were 10 articles that met the following criteria: (a) involved assessment and/or instruction that measured performance on a general education task; (b) targeted students in grades $6^{\text {th }}$ through $12^{\text {th }}$ with learning disabilities; (c) included technology-based assessments/interventions as the independent variable; and (d) was published in journals that measured effects on students' performance. In all 10 studies reviewed, technology-based practices were combined with other instruction practices including study guides, content enhancements, and learning strategies. Hypertext and hypermedia software programs, multimedia software, and videodisc instruction involving contextualized learning were the practices 
found to be the most promising for academic performance of students with learning disabilities.

Scruggs, Mastropieri, Berkeley, and Graetz (2010) completed a secondary content area instruction research synthesis for students with disabilities. Seventy studies were identified, analyzed, and coded for variables. The selected studies included over 2,400 students as participants and an overall effect size of 1.00, indicating promising evidenced-based practices to be used at the secondary level in content area instruction. Those practices include explicit instruction, learning strategies (study skills instruction), mnemonic instruction, graphic organization, study aids (guides, advance organizers), peer mediation (peer tutoring, cooperative learning), hands-on/activity-based activities (investigations), and computer-assisted instruction.

Bost and Riccomini (2006) outlined 10 effective teaching principles and their relation to achievement leading to school completion for students with disabilities: active engagement, grouping for instruction, scaffolding, organizing and activating knowledge, providing the experience of success, content coverage and opportunity to learn, addressing forms of knowledge, teaching sameness, and strategic and explicit instruction. The authors believe that when these research-validated practices are implemented systematically and consistently, students with disabilities will make academic gains and experience school success in general education.

Graphic organizers, mnemonic strategies, formative evaluation (providing academic feedback), and activating background knowledge were also included as evidence-based practices used in a study to increase the use of instructional strategies that have a strong empirical foundation (Duchnowski, Kutash, Sheffield, \& Vaughn, 2006). 
The authors used a collaborative approach to increase the use of evidence-based instructional strategies by teachers of students in special education programs in a middle and high school. Reducing the gap from research to practice in special education was the aim of this research demonstration project.

Wolgemuth, Cobb, and Alwell (2008) studied the relationship between academic performance and mnemonic instruction through a systematic review of 20 studies intervening with 669 secondary students with disabilities. Their findings strongly support the use of mnemonics in the improvement of academic performance across study methods, student ages, disabilities, and educational settings. In this study, academic performance was typically measured by recall of facts or word meanings.

In another study, the researchers explored the effects of strategy instruction on the test performance of secondary students with high-incidence disabilities (Carter et al., 2005). Participants included 38 students with high-incidence disabilities that attended a high school in a large, urban school district. The students received strategy instruction in test-taking skills over a period of six weeks. After the intervention, small but significant decreases in test anxiety (as measured by the Test Anxiety Inventory) and increases in test performance (as measured by the Simulated Tennessee Competency Achievement Program) were demonstrated.

Few studies have been conducted recently that have examined general evidencebased practices for use with students with disabilities. For the purpose of this study, only those articles on effective teaching practices across various subject areas and relevant to secondary students with disabilities were included. Consequently, the included studies have similar findings. Graphic organizers, mnemonic strategies, peer-mediated activities, 
study aids, activity-based learning, strategy instruction, explicit instruction, activating knowledge, and technology-based practices are all categories of identified best practices for academic performance found in more than one research study reviewed in this section. Therefore, the nine strategies will be used in the current study as indicators of instructional best practices.

\section{Culturally Responsive Teaching}

Culturally responsive teaching (CRT) is an educational practice that takes into account a student's perspectives, cultural characteristics, and experiences as channels for effective teaching (Gay, 2002b). The materials, methods, structures, as well as the content of instruction are all involved in CRT (Voltz, Brazil \& Scott, 2003). It is based on the assumption that academic skills and knowledge are more interesting, meaningful, and are learned thoroughly and more easily, when they are situated within student's frame of reference and lived experiences. When ethnically diverse students are taught through their own cultural filters, their academic achievement will improve (Gay, 2002b; Gay, 2004). CRT is rooted in multicultural education, a tool for educational excellence and equality conceived in the 1960's during the civil right movement. Gay (2004) explains that the mission of multicultural education is to "genuinely 'integrate' educational programs, procedures, and practices with the ethnic, racial, cultural, and social diversity that characterizes U.S. Society" (p. 193). Multicultural education extends culturally and linguistically diverse students the right to learn within the context of their own culture (Gay, 2004).

If more students received culturally responsive teaching, there would be a reduction of disproportionate representation among CLD students (Klingner et al., 2005), 
which includes Black students. Due to the disproportionate referrals to special education, academic underachievement, and disciplinary actions, CLD students display the greatest need for differentiated, intensified, high quality instruction (Cartledge \& Kourea, 2008). According to Chamberlain (2005), culturally and linguistically diverse means culturally and linguistically different from the dominant or mainstream culture and language reflective of the values of the early people who established this country. Ford and Kea (2009) actually prefer the term "culturally different" over "culturally diverse". Since everyone has a culture, "culturally diverse" describes every group. The authors propose that frustrations, tensions, and misunderstandings stem mostly from "cultural differences".

CRT is pedagogy that uses cultural referents to convey knowledge and skills that empower CLD students in intellectual, emotional, and social ways. It recognizes the important role culture plays in how CLD students obtain, examine, and interpret information; an experience that allows students to keep their cultural integrity while at the same time pursuing academic excellence (Howard, 2001). Increasing the academic achievement of CLD students is possibly the most important goal of culturally relevant teaching (Howard, 2003). The focus is ensuring success and learning, whether the term culturally responsive 'teaching', 'pedagogy', or 'instruction' is used (Ford \& Kea, 2009).

Over five years, Santamaria (2009) used a qualitative case study to examine CRT and differentiated instruction (DI) frameworks as complementary teaching practices for English language learners and culturally diverse students. The setting included two elementary schools in California with high levels of CLD student populations. The schools were selected because they both were narrowing achievement gaps and 
displaying high levels of academic achievement. Data collection included recorded discussions among administrators, teachers, parents, and students as well as observations and relevant supporting documents. The data was analyzed by coding information pertinent to the general features CRT and DI and organizing them into larger themes positioned by the CRT and DI literature. The author concludes that the best teaching practices are those that take into account all students within a classroom and attend to their cultural, linguistic, socioeconomic, and academic differences. These practices along with the design of hybrid pedagogies are crucial for student achievement.

Gay (2002b) examined five key components of CRT based on practical experiences, research findings, theoretical claims, and personal narratives of educators researching and working with Latino, Asian, African, and Native American underachieving students. The first component is developing a cultural diversity knowledge base. This includes understanding the contributions and cultural traits of different ethnic groups, as well as attaining specific factual information regarding their cultural particularities. The second component is designing culturally relevant curricula. This involves converting the first component into instructional strategies and curriculum designs that are culturally responsive. The third component is demonstrating cultural caring and building a learning community; that is, fostering classroom climates for ethnically diverse students that are conducive to learning. Cultural caring means that teachers set high expectations and accept nothing less because they are just that concerned about achievement of ethnically diverse students. The fourth component is cross-cultural communications. Being that the intellectual thoughts of students are culturally encoded, teachers are more effective when they can decipher these codes and 
communicate with students. The final component is cultural congruity in classroom instruction, which deals with instructional delivery. It is matching the learning styles of diverse students to instructional techniques by using cultural characteristics as the determining criteria. The author acknowledges that the five critical components of CRT examined in this article are not inclusive.

To study the prevalence of the domains and components of a Culturally Relevant and Responsive Educational (CRRE) Program in schools and classrooms serving African American learners, Maddahian (2004) investigated practices in the Los Angeles Unified School District (LAUSD). The research occurred in four local districts of LAUSD that enroll almost $85 \%$ of African American students. Data were collected from a random sample of ten schools per district including 16 elementary, 12 middle, and three high schools. For two consecutive days, one middle English teacher, one high school English teacher, one math teacher, and one social studies teacher, as well as two $5^{\text {th }}$ grade teachers at the elementary level, were observed for at least half a day or four periods. Observation forms and detailed field notes were used by fifteen trained data collectors to document the presence or absence of CRRE instruction in the following domains: Knowledge and Experience, Social and Emotional, Quality Instruction and Curriculum, Instructional Strategies, Relevant Educational Resources, Diagnosis and Assessment, and Parent and Community Involvement.

Findings show that less than half of the observations indicated teachers engaged in elements associated with the Knowledge and Experience domain. For the Social and Emotional domain, there was little evidence of mutual respect and acceptance, high expectations, respect for cultural diversity, and appropriate classroom management. Less 
than $25 \%$ of the observations documented classroom materials and décor reflective of student diversity in the Relevant Educational Resources domain. For the Quality Instruction and Curriculum domain, the use of comprehensible standards and multicultural content as well as attention to poverty and diversity issues was low. The use of cooperative learning, instructional conversations, scaffolding, and active learning were confirmed in over $40 \%$ of the observations for the Instructional Strategies domain. In the Diagnosis and Assessment domain, ten percent of elementary, 18\% of English, 22\% of social studies, and $2 \%$ of math teachers displayed alternative assessment methods. Additional testing time and student support was evidenced in $31 \%$ of the elementary, $40 \%$ of English, $15 \%$ of social studies, and $28 \%$ of math classroom observations. As for the Parent and Community Involvement domain, parental presence occurred only when parents were called due to discipline issues or discussed homework; community involvement and presentations were rare. Recommendations include suggestions for a CRRE training and instruction model for program and staff development. In light of the CRRE model, a blueprint for evaluators to analyze their educational practices is provided.

\section{Learning Styles of Black Students}

Black students typically prefer a relational, holistic, and field-dependent style of learning. Creativity, focus on people, variation, divergent thinking, freedom of movement, and inductive reasoning all characterize relational learners. Holistic learners flourish in content linked to a larger whole, and their primary approach of information induction is kinesthetic so concreteness is necessary to support learning new skills/content. Field-dependent learners rely on external cues from the environment, are 
people-oriented, are perceptive thinkers, and use social contexts to retain information (Berry, 2003; Obiakor \& Ford, 2002).

Black students are usually visual learners and pull from their day-to-day experiences to facilitate learning. They often organize information and experiences based on how things relate to each other. Black learners typically prefer group over individual and cooperative over competitive learning experiences. Improvisation and experimentation with others and the environment are also common preferences for Black students (Berry, 2003; Obiakor \& Ford, 2002).

\section{CRT for Students with Disabilities}

Cartledge and Kourea (2008) discuss the culturally effective instructional principles that should be reflected in classrooms for CLD students with and at risk for disabilities based on empirical literature. The authors state that culturally effective instruction should not only reveal a sense of urgency, but should be appropriately paced with high levels of active student responding. Additionally, culturally effective instruction should include the continuous monitoring of academic progress, delivery of timely feedback, and the creation of positive classroom environments with communities of learners. A teacher using what they know about their CLD students to give them access to learning is another culturally responsive teaching practice. Other practices include building on the cultural strengths of students, utilizing various assessments, and assisting students to study the curriculum from multiple viewpoints (Villegas \& Lucas, 2002).

Similarly, Gay (2002a) states that by using instructional practices that reflect the cultural experiences and perspectives of ethnically diverse students with and without 
disabilities, teachers can significantly improve their quality of education. This involves multicultural curriculum, classrooms with culturally pluralistic climates, cultural consciousness of teachers, and diverse communities of learners. Without these components of CRT, learning can never be optimal for these students who are not part of the schools majority and mainstream.

Hart (2009) describes research-based academic strategies for CLD students with special needs. Comprehension strategy instruction, reciprocal teaching, semantic mapping, priming, marginal notes, advance organizers, and multiple grouping strategies are all included as strategies to facilitate learning for this population of students. To help educators of CLD students with disabilities and struggling learners, Chamberlain (2005) compiled a list of recommendations with the intent to also deal with misidentification and overreferral problems. Included are recommendations that teachers (a) develop cultural consciousness, (b) become aware of their own cultural background and cultural clashes (c) become knowledgeable about the influence of culture on the teaching/learning process, (d) hold high expectations for all learners, (e) avoid blaming others for student underachievement, (f) reflect on teaching practices, (g) gather information about your students and build relationships with students and parents, (h) understand the interaction of language, culture, and disability, and (i) utilize an integrated approach to instruction and various strategies with CLD students. CRT should be available to all students, regardless of their educational placement.

The history, goals, and key components of culturally responsive teaching practices are important for this unique population of students. Inherently, CRT is the instructional principles and research-based academic strategies that facilitate learning for 
culturally and linguistically diverse students with disabilities. What is equally important as CRT and students with disabilities is educational placement and students with disabilities.

\section{Educational Placement of Secondary Students with Disabilities}

The Florida State Department of Education (2000) released a technical assistance paper to address concerns in Florida school districts on determining the most appropriate educational placement for students with disabilities. Using the LRE provision component of IDEA, the paper lists three procedures that must be adhered to when making a placement decision: a continuum of optional placements are available to meet the needs of students, placement is determined annually (at least), and placement decisions are made by a group of people knowledgeable about the student and placement options. In addition, the paper explicitly states the following factors that should be considered when making placement decisions:

1. The student is educated in the school that he or she would attend if nondisabled.

2. In selecting the appropriate placement, consideration must be given to any harmful effects on the student or on the quality of services he or she needs.

3. A student with a disability is not removed from education in age-appropriate regular classrooms solely because of needed modifications in the general curriculum.

4. The student's placement options must not be based solely on the student's eligibility category, disabling condition, administrative convenience, or label.

5. The school district must ensure that each student with a disability has the opportunity to participate as appropriate in nonacademic and extracurricular services and activities (FLDOE, 2000 p. 6). 
Skiba et al. (2006) investigated the extent to which the overrepresentation of Black students in more restrictive special education settings is attributable to their overrepresentation in disability categories more likely to be serviced in more restrictive educational environments. Within five disability categories (emotional disturbances, mild mental retardation, moderate mental retardation, learning disabilities, and speech/language impairments), Black students were overrepresented in more restrictive educational environments and underrepresented in less restrictive environments relative to all other students with the same disability. Disproportionality was most evident in those disability categories served primarily in general education settings. In other words, Black students with disabilities who are overrepresented in the disability categories studied by the authors are more likely to be served in more restrictive educational environments. Given the social consensus regarding inclusion, Skiba et al. believe that disproportionality in restrictiveness of educational environment may represent a more serious challenge than disproportionality in disability categories.

In fact, recent efforts to challenge exclusionary practices in special education through increased "inclusion" have resulted in resistance similar to that expressed in response to school desegregation shortly after Brown v. Board of Education in 1954. Ferri and Connor (2005) explored the interplay between racism and ableism in the resistance to school desegregation and inclusion of students with disabilities in general education. The researchers argue that race and disability should be understood primarily as interactive social constructs and not distinct biological markers.

Classroom placement relative to the academic achievement of students with SLD in secondary classroom settings was the purpose of a descriptive exploratory study 
conducted by Fore, et al. (2008). The Multilevel Academic Survey Test Grade Level Short Form was used to assess 57 high school students with learning disabilities in math and reading. Scores were examined relative to each participant's grade level, inclusive or non-inclusive placement and the number of general and special education classes attended. No significant evidence was revealed to indicate varied achievement based on placement.

However, the research of Rea et al. (2002) indicates something quite different. This mixed methods study investigated the relationship between inclusive and pull-out special education programs for students with learning disabilities as it relates to academic and behavior outcomes. Comparability of the two groups was established using demographic data including age, gender, ethnicity, socioeconomic status, and IQ scores. The special education inclusive and pull-out models at two middle schools were described using qualitative and quantitative methods. Functional definitions were provided by examining classroom accommodations, Individual Education Plan goals and objectives, and teacher collaboration. Course grades, suspension data, standardized and criterion test scores, and attendance data were also analyzed. The results not only indicated that the two programs differed significantly, but that students served in inclusive settings earned higher grades, had higher school attendance, committed no more behavioral infractions, and achieved higher or comparable scores on standardized tests than students serviced in the pullout setting.

To examine the relationship between educational placement and performance of students with disabilities, Luster and Durrett (2003) studied students primarily served in general education and indicators of student performance and outcome variables. The 
exploratory study investigated whether there was a correlation between the inclusion of these students and their performance on fourth and eighth grade state level assessments as well as graduation rates of students with disabilities. Using pre-existing data reports and performance profiles, analyses were completed for 66 school districts in Louisiana. Results indicate significant correlations for general education placement and eighth grade state level assessments as well as diploma rates. This suggests that more inclusive placements are linked to higher graduation rates and passing test scores in eighth grade.

Similarly, Cawley et al. (2002) investigated the behavior and science achievement of students with and without disabilities attending inclusion science classes and general science classes. Students involved in the study were from an inner-city junior high school and included 114 participants. Discipline referrals, final district science exams, and final grades were used for assessment. Results indicated that the academic performance of students with disabilities was comparable to the general education students and their behavior did not pose a problem in the general setting.

Six secondary students with mild mental impairments participated in a study to examine the impact of educational placement on classroom interactions across three school districts in Michigan (Bouck, 2006). The researcher collected data by following each student three times for an entire school day. This procedure included attending their classes, lunchtime, and all other activities integrated into their regular school day. Additionally, each participant's education files were analyzed and a semi-structured interview was conducted with each student and their primary special education teacher. The interviews were used to gather data regarding perspectives on interactions in different educational contexts. The general education classes ranged from zero to two 
among the six participants, typical of students with mental impairments according to the special education teachers' comments. Results reveal that the students had fewer interactions (with peers and adults) in general education than special education settings.

With a focus on secondary school students with learning disabilities, the National Center for Special Education Research (Newman, 2006) collected data to address the enrollment and experiences in general education as well as their academic performance. Some of the relevant key findings for students with learning disabilities include:

1. Students are equally likely to have language arts in special and general education settings.

2. Students more likely to take math, social studies, and science in general education.

3. About $35 \%$ of students receive the standard grade-level curriculum used for nondisabled peers in their academic setting.

4. Students experience instructional grouping with a frequency similar to that of the whole class.

5. Students participate less actively than typical peers in their general education classes.

6. Approximately $78 \%$ of students keep up with others in their class as reported by their teachers.

Handler (2003) analyzed visual and quantitative archival data to evaluate educational environmental placement trends at the national and state level for students ages 6-11 or 12-17 under one of the four high incidence disabilities categories (i.e., Specific Learning Disabilities, Mental Retardation, Emotional Disturbance, or Speech 
and Language Impairments). The data were collected from the Office of Special Education Programs (OSEP) Annual Reports to Congress on the Implementation of the IDEA and OSEP databases from 1989-1999. Results indicate increases in more inclusive placements, especially for students with SLD or Speech and Language Impairments in the decade following the Regular Education Initiative. However, the data reported to OSEP did not reflect the placement trends at the state level which demonstrate substantial variation. For instance, Florida's placement trends fluctuated across the decade.

Descriptive studies of nine high schools across four states illustrate the context and outcomes of programs for students with disabilities on standard curriculum tracks. The schools were equally represented across rural, urban, and suburban areas. Using classroom observations, interviews, and/or questionnaires, the results indicate that only one of the schools used research-based methods to teach strategies for success. This was also the only school with a vision and standard procedures for including students with disabilities in the general education curriculum. The highest satisfaction rating was given to this same school based on the data from general educators and students with disabilities. Data collected indicated that most of the other schools educated students with disabilities in separate, special education classrooms or in low-track classes geared toward low achievers. Research-based programs and technology were not being used, satisfaction ratings were low, and students with disabilities were not achieving (Schumaker et al., 2002).

The literature review on educational placement explains the factors that should be considered when making placement decisions and compares the resistance to inclusion to the resistance experienced during school desegregation. It is also revealed that Black 
disproportionality is most evident in the disability categories served primarily in general education settings. Some studies favored inclusive settings for students with disabilities, while others stated no significant evidence to indicate one placement over another. The evidence from the research on efficacy of one placement over another is found to be inconclusive, methodologically flawed, and scarce (Zigmond, 2003). Arguably, where students are educated is not more important than the individualized planning of each student; suggesting that this should embody the placement-decision making process.

\section{Chapter Summary}

The literature review shed light on the factors that positively impact academic achievement for Blacks, the disadvantage of measuring Black student achievement through high stakes testing, and reasons for differences in math achievement of Black students as compared to students of other races. The literature also described the instructional practices found to be successful for students with disabilities at the secondary level. In addition, the research surrounding educational placement is inconclusive and does not preference one placement over another. However, Black students were overrepresented in more restrictive educational environments and underrepresented in less restrictive environments relative to all other students with the same disability.

The literature reveals a lack of research in achievement and placement as it relates to Black students with disabilities, particularly in urban secondary settings. This creates an even bigger problem for students who are already overrepresented in special education. The current study is necessary to shed light on the achievement of this population as it relates to educational placement and the reported use of instructional 
practices. Research in this area may influence future decision-making that considers Black students' achievement first. 


\section{Chapter III}

\section{METHODS}

The purpose of this study was to investigate the relationship between inclusive and resource educational placement, instructional best practices, and the academic achievement of Black students with specific learning disabilities (SLD) in urban secondary settings. This study sought to determine whether Black students with SLD in urban secondary school settings serviced in inclusive language arts and math classes demonstrate a difference in achievement gains as evidenced by growth in scale scores when compared to Black students with SLD serviced in resource language arts and math classes. In addition, this study investigated the relationship between the reported use of instructional best practices and achievement gains with this population of students while taking into account their educational placement.

This chapter presents the research questions, hypotheses, and the context of the study as well as a description of the research design, setting, and population including the sample size. The variables are defined and the instrumentation is discussed. In addition, the research procedures are identified and the data analysis is explained.

\section{Research Questions}

1. Is there a significant difference in math achievement gains of Black students with SLD serviced in secondary resource settings as compared to inclusive educational classroom placements?

2. Is there a significant difference in reading achievement gains of Black students with SLD serviced in secondary resource settings as compared to inclusive educational classroom placements? 
3. What is the relationship between the educational placement of Black students with SLD and the reported use of instructional best practices?

4. Is there a relationship between the reading achievement gains of Black students with SLD and the reported use of instructional best practices?

5. Is there a relationship between the math achievement gains of Black students with SLD and the reported use of instructional best practices?

\section{Research Hypotheses and Models}

The hypotheses and models for each research question are described below. The codes and scales used in each model can be found in Appendix B.

Research Hypothesis 1. There is a significant difference in math achievement gains of Black students with SLD serviced in secondary resource settings as compared to inclusive educational classroom placements.

Alternative Hypothesis 1. There is a significant difference in math achievement gains of Black students with SLD serviced in secondary resource settings as compared to inclusive educational classroom placements when controlling for gender.

Model: $\quad$ YAGM $=\mathrm{a}_{0} \mathrm{U}+\mathrm{a}_{1} \mathrm{EPL}+\mathrm{a}_{2} \mathrm{GEN}+\mathrm{E}_{1}$

Research Hypothesis 2. There is a significant difference in reading achievement gains of Black students with SLD serviced in secondary resource settings as compared to inclusive educational classroom placements.

Alternative Hypothesis 2. There is a significant difference in reading achievement gains of Black students with SLD serviced in secondary resource settings as compared to inclusive educational classroom placements when controlling for gender.

Model: $\quad$ YAGR $=\mathrm{a}_{0} \mathrm{U}+\mathrm{a}_{2} \mathrm{EPL}+\mathrm{a}_{3} \mathrm{GEN}+\mathrm{E}_{2}$ 
Research Hypothesis 3. There is a relationship between the educational placement of Black students with SLD and the reported use of instructional best practices.

\begin{tabular}{|c|c|}
\hline Model: & $\begin{array}{l}Y G O=a_{0} U+a_{3} E P L+E_{3} \\
Y A B L=a_{0} U+a_{4} E P L+E_{4} \\
Y M S=a_{0} U+a_{5} E P L+E_{5} \\
Y P M A=a_{0} U+a_{6} E P L+E_{6} \\
Y A K=a_{0} U+a_{7} E P L+E_{7} \\
Y S A=a_{0} U+a_{8} E P L+E_{8} \\
Y S I=a_{0} U+a_{9} E P L+E_{9} \\
Y E I=a_{0} U+a_{10} E P L+E_{10} \\
Y T B P=a_{0} U+a_{11} E P L+E_{11} \\
Y C R T=a\end{array}$ \\
\hline
\end{tabular}

Research Hypothesis 4. There is a relationship between the reading achievement gains of Black students with SLD and the reported use of instructional best practices.

Alternative Hypothesis 4. There is a relationship between the reading achievement gains of Black students with SLD and the reported use of instructional best practices when controlling for gender.

Model: YAGR $=\mathrm{a}_{0} \mathrm{U}+\mathrm{a}_{1} \mathrm{RGO}+\mathrm{a}_{2} \mathrm{RABL}+\mathrm{a}_{3} \mathrm{RMS}+\mathrm{a}_{4} \mathrm{RPMA}+\mathrm{a}_{5} \mathrm{RAK}+\mathrm{a}_{6} \mathrm{RSI}+$ $a_{7} R E I+a_{8} R T B P+a_{9} R S A+a_{10} R C R T+a_{11} G E N+E_{12}$

Research Hypothesis 5. There is a relationship between the math achievement gains of Black students with SLD and the reported use of instructional best practices.

Alternative Hypothesis 5. There is a relationship between the math achievement gains of Black students with SLD and the reported use of instructional best practices when controlling for gender. 
Model: $\mathrm{YAGM}=\mathrm{a}_{0} \mathrm{U}+\mathrm{a}_{1} \mathrm{MGO}+\mathrm{a}_{2} \mathrm{MABL}+\mathrm{a}_{3} \mathrm{MMS}+\mathrm{a}_{4} \mathrm{MPMA}+\mathrm{a}_{5} \mathrm{MAK}+\mathrm{a}_{6} \mathrm{MSI}+$ $\mathrm{a}_{7} \mathrm{MEI}+\mathrm{a}_{8} \mathrm{MTBP}+\mathrm{a}_{9} \mathrm{MSA}+\mathrm{a}_{10} \mathrm{MCRT}+\mathrm{a}_{11} \mathrm{GEN}+\mathrm{E}_{12}$

\section{Context of Study}

This study took place in Miami-Dade County Public Schools (M-DCPS), located in south Florida. M-DCPS is the fourth largest school district in the U.S. The enrollment from Pre-Kindergarten through $12^{\text {th }}$ grade was 345,406 for the 2009-2010 school year with $11 \%$ being students with disabilities.

For the 2010-11school year, 51\% of students with disabilities in M-DCPS ages 621 spent $80 \%$ or more of their school week with nondisabled peers, $26 \%$ spent between $40 \%$ and $80 \%$ of their school week with nondisabled peers, and $20 \%$ spent less than $40 \%$ of their week with nondisabled peers. The remaining $3 \%$ of students with disabilities were serviced in separate environments/schools. On the other hand, the state of Florida reported $69 \%$ of students with disabilities ages $6-21$ spent $80 \%$ or more of their school week with nondisabled peers, $12 \%$ spent between $40 \%$ and $80 \%$ of their school week with nondisabled peers, and $15 \%$ spent less than $40 \%$ of their week with nondisabled peers while the remaining $4 \%$ were educated in separate environments/school (FLDOE, 2011a).

Additionally, M-DCPS did not meet two of the three 2009-10 state-level goals under the least restrictive environment indicator. This means that the district did not increase the percentage of students with IEPs removed from regular class placement for less than $21 \%$ of the day, or decrease the percentage removed from regular class placement for greater than $60 \%$ of the day to the targeted percentage for that year. The 
district also failed to decrease the percentage of students with IEPs served in public or private separate schools, residential placements, or homebound or hospital placements. Additionally, M-DCPS did not meet the target percentage of students with disabilities demonstrating proficiency in reading or math (FLDOE, 2011a). Furthermore, both subgroups of Blacks and students with disabilities in M-DCPS did not meet math or reading proficiency for the 2008-09 school year. Approximately 57\% of Black students and $69 \%$ of students with disabilities in M-DCPS were below grade level in reading, and $51 \%$ of Black students and $65 \%$ of students with disabilities were below grade level in math. In addition, neither student subgroup met adequate yearly progress in math or reading (FLDOE, 2011b).

\section{Research Design}

An ex post facto research design was used to investigate the relationship between educational placement, instructional best practices, and academic achievement of Black students with specific learning disabilities (SLD). This non-experimental design was chosen because the study involves comparison groups that already exist yet differ on the independent variable, which is not under the control of the researcher and cannot be manipulated (McMillan \& Schumacher, 2001). This design demonstrates relationships and does not attempt to establish causation. The most valid and powerful ex post facto designs are those guided by hypotheses and tests for alternative hypotheses. Since this type of ex post facto research achieves greater internal validity, this study utilized this specific design as it attempted to control for possible alternative explanations for relationships (Newman, Newman, Brown, \& McNeely, 2006). 
For this study, the dependent variable (achievement gains) and the independent variables (educational placement, instructional best practices) and gender cannot be manipulated. With ex post facto research, the results are easily generalized to the general population because the sample was studied without imposing experimental controls (Newman et al., 2006).

The research questions addressed possible rationales for the value of the dependent variable obtained and identified alternative hypotheses that may provide an explanation of the relationship. This study explored relationships between educational placement, instructional best practices, and academic achievement of Black students with specific learning disabilities (SLD) in urban secondary settings.

\section{Setting}

M-DCPS is divided into five main regions. There are 88 middle and K- 8 Center schools within the district. M-DCPS enrolled 345,406 Pre-Kindergarten through 12th grade students for the 2009-10 school year with $11 \%$ being students with disabilities. Although Black students are $25 \%$ of the total district population, they comprise $28 \%$ of those with an identified disability. This is similar to the state of Florida with Blacks being $23 \%$ of the total population yet making up $26 \%$ of students with disabilities. Black students comprise $25 \%$ of M-DCPS students with a primary exceptionality of SLD. For students with SLD in M-DCPS, the risk ratio of 1.04 for Blacks is slightly lower than the state's risk ratio of 1.07 (FLDOE, 2011a).

\section{Population and Sample Size}

The population for this study consisted of eighth-grade, Black students with SLD. Black students with SLD attending center schools, charter schools, or alternative 
education schools were not included as their programs differ from traditional middle school programs for students with disabilities. Students within this sample had both 2009-2010 standardized math and reading achievement scores and their math and reading instruction both occurred in the same placement for the 2010-2011 school year. Students who received language arts instruction in a different placement than their math instruction were excluded from the sample. For example, if a student was in the resource room for language arts but received math instruction in an inclusive classroom, he or she was not included in the sample.

Approximately 314 eighth grade Black students with SLD met criteria for this study. Table 1 provides the details of the characteristics of the sample. A little over half of the students were in a resource setting and most of the students were male.

Table 1

Student Demographic Frequencies Table $(N=314)$

\begin{tabular}{lrc}
\hline Student Demographics & $n$ & Percent \\
\hline Gender & & \\
$\quad$ Male & 216 & $68.8 \%$ \\
$\quad$ Female & 98 & $31.2 \%$ \\
Educational Placement & & \\
$\quad$ Inclusive & 150 & $47.8 \%$ \\
$\quad$ Resource & 164 & $52.2 \%$ \\
\hline
\end{tabular}

For analyses involving multiple regressions, Green (1991) recommends a sample size of at least 5 and up to 50 participants per variable. For this study, which includes 13 variables, a minimum sample size of 65 is recommended; that is, no less than 65 
participants per group totaling 130 altogether. Approximately 314 students met criteria for this study.

An estimate of power was calculated to determine how well a medium $\left(\mathrm{f}^{2}=.15\right)$ effect size would be detected as identified by Cohen (1970) and McNeil, Newman, and Kelly (1996). With an alpha level set at .05 and $\mathrm{N}=314$, the estimated power is approximately 0.99 . That is, the analysis would be able to detect a difference of a medium effect size, $99 \%$ of the time.

Identified content area teachers of select students in the sample were used to collect data on the reported use of instructional practices during the 2010-2011 school year. The Teacher Instructional Practices Survey (see Appendix A) was developed to gather this data. Content area teachers' participation in this study was voluntary. All possible measures were taken to protect student and teacher confidentiality by using numerical codes for surveys and student demographic data. By doing so, teacher names and school locations were not identified on the surveys nor were any reference to names or school locations used in this study.

Data related to instructional best practices for 78 student participants were provided by the completion of 36 Teacher Instructional Practices Surveys as indicated in Table 3. Of the 36 surveys, 22 provided data for language arts instruction (15 general educators, 6 special educators, 1 other) and 14 provided data for math instruction (9 general educators, 4 special educators, 1 other) during the 2010-2011 school year. Approximately 17 teachers were certified in reading and 11 teachers were certified in math. Data in Table 2 are from part I of the survey. 
Table 2

Teacher Survey Frequencies Table

\begin{tabular}{lrr}
\hline Teacher Demographics & $n$ & Percent \\
\hline Teacher Instructional Practices Survey & $N=36$ & \\
Reading & 22 & $61.1 \%$ \\
Math & 14 & $38.9 \%$ \\
Reading Certification & $N=22$ & \\
Reading & 17 & $77.3 \%$ \\
Middle Grades Integrated Curriculum & 2 & $9.1 \%$ \\
No Response & $3=22$ & $13.6 \%$ \\
Reading Teaching Role & 15 & $68.2 \%$ \\
General Educator & 6 & $27.3 \%$ \\
Special Educator & 1 & $4.5 \%$ \\
Other & $N=14$ & \\
Math Certification & 11 & $78.6 \%$ \\
Math & 3 & $21.4 \%$ \\
No Response & $N=14$ & \\
Math Teaching Role & 9 & $64.3 \%$ \\
General Educator & $4.1 \%$ \\
Special Educator & 1 & $28.6 \%$ \\
Other & 3 & \\
\hline
\end{tabular}

\section{Variables}

The variables for this study are educational placement, achievement gains, and instructional best practices (see Appendix B for codes and scales). This study also controlled for the effect of student gender as an alternative hypothesis. 


\section{Educational Placement}

Placement is defined as either a resource or inclusive classroom. Resource classrooms service only students with disabilities and are taught by a special educator. Inclusive classrooms service both students with and without disabilities and are taught by a general educator.

\section{Achievement Gains}

Growth in achievement is defined as the increase in scale scores from the 20092010 to the 2010-2011 Florida Comprehensive Assessment Test (FCAT) SSS in Reading and Math. Scale scores, which range from 100 to 500, were used for this study to measure achievement gains because they provide more detailed information regarding growth than FCAT levels which only range from 1 to 5 (FLDOE, 2009).

\section{Instructional Best Practices}

Instructional best practices are the strategies used by teachers during the 20102011 school year as reported on the Teacher Instructional Practices Survey (see Appendix A). The instructional strategies used in this study are found in the literature to be general best practices for secondary students with disabilities, not specific to any particular subject area. Also included as a best practice is the use of culturally responsive teaching (CRT).

Graphic organizers. Any type of visual organization/representation that makes relationships between concepts and related facts more apparent and arranges information in a way that facilitates learning, is defined as a graphic organizer (Anderson et al., 2004; Hughes et al., 2003; Scruggs et al., 2010). Some examples include Venn diagrams, flow charts, and concept maps. 
Mnemonic strategies. A sentence, word, technique or picture device used to link new information to student's existing knowledge to facilitate retrieval is a mnemonic strategy. The keyword and acronym methods are two forms of mnemonic instruction. The keyword method connects an unknown word to a similar-sounding known word. The acronym method assigns a known specific word/idea to each letter in the word (Anderson et al., 2004; Scruggs et al., 2010; Wolgemuth et al., 2008; Hughes et al., 2003).

Peer-mediated activities. Involving students in an instructional role with their peers is considered a peer-mediated activity. Some examples include cooperative learning and class wide peer tutoring (Anderson et al., 2004; Scruggs et al., 2010; Hughes et al., 2003).

Study aids. Study aids are teacher-prepared handouts to assist students with learning content by focusing their attention on critical information. Guided notes, advance organizers, and study guides are some examples (Anderson et al., 2004; Scruggs et al., 2010; Hughes et al., 2003).

Activity-based learning. This approach to instruction allows students to work directly with relevant materials rather than learning mainly from a text as they investigate concepts (Anderson et al., 2004; Scruggs et al., 2010).

Strategy instruction. When students are taught to apply a series of steps necessary to solve a problem/complete a task, it is known as strategy instruction (Hughes et al., 2003). This type of instruction is about teaching students learning strategies or "how to learn" (Bost \& Riccomini, 2006). For example, students can be taught notetaking strategies, self-monitoring strategies, summarization strategies, self-questioning strategies (Scruggs et al., 2010) and/or test-taking strategies (Carter et al., 2005). 
Explicit instruction. Teaching explicitly means that the process of learning is highly organized and task oriented; information is presented to students in a clear and direct method (Bost \& Riccomini, 2006). Teaching in small steps, providing guided practice, and allowing independent practice are three steps of explicit instruction (Scruggs et al., 2010).

Activating knowledge. When teachers combine what students know and understand with new information, it is defined as activating knowledge (Bost \& Riccomini, 2006). Activating background knowledge has been considered as an effective structured reading strategy to increase reading comprehension (Duchnowski et al., 2006).

Technology-based practices. Using the computer and/or other expert systems as the means to provide instruction and analyze student learning is a technology-based practice (Maccini et al, 2002). These practices may include videodisc instruction, multimedia software (Scruggs et al., 2010), and hypertext and hypermedia software programs.

Culturally Responsive Teaching. CRT is an instructional practice that takes into account a student's perspectives, cultural characteristics, and experiences as channels for effective teaching (Gay, 2002b) with a focus on ensuring success and learning (Ford \& Kea, 2009). An example would be incorporating student interests into instructional lessons.

\section{Instrumentation}

To collect data on the instructional practices within each educational placement, a Teacher Instructional Practices Survey was created (see Appendix A). This instrument consisted of statements related to effective instructional strategies. The statements are 
related to the 10 strategies found in the literature to be general best practices for secondary students with disabilities, not specific to any particular subject area, including CRT. Using this instrument, the researcher sought to determine if the identified teachers reported using any practices in the following categories during the 2010-2011 school year: graphic organizers, study aids, mnemonic strategies, peer-mediated activities, activating knowledge, activity-based learning, strategy instruction, explicit instruction, technology-based practices, culturally responsive teaching.

\section{Validity}

Expert judge validity techniques (Newman \& Newman, 1994) were used to obtain validity estimates by getting feedback from local experts in the field of learning disabilities and inclusion. The survey was shared with the Executive Director of Curriculum and Intervention and four Curriculum Support Specialists (CSS) from the school district's Division of Special Education. They are considered experts in the field because each has significant experience teaching students with disabilities and coaching general and special educators on strategies to increase achievement for this population of students, particularly those with SLD.

Following a thorough explanation of its purpose and defining all ten best practices, the experts examined the survey to determine if the statements actually addressed the variable they intended. The experts involved also reviewed the survey with a focus on format and usability. This was done to obtain an estimate of the content validity of the survey instrument. Although $100 \%$ of the experts provided feedback that the survey questions addressed the constructs they intended, their suggestions and constructive feedback resulted in changes to the survey. One of the changes was adding 
additional open-ended questions to obtain more detailed information of the teachers' beliefs on how and what practices/strategies they used in their classroom this school year. The second change involved providing an opportunity to describe or provide examples of their response to each Likert-scale statement.

\section{Reliability}

The Cronbach's alpha coefficients measure of internal consistency was used to attain estimates of reliability (Newman \& Newman, 1994) for the survey items. The survey was completed by a group of 30 high school content area teachers to assess the consistency of results across items within the survey. The high school teachers' participation did not take away from the eighth grade content area teachers identified for this study. The reliability coefficients for the high school teacher surveys were calculated at $r=.823$. Test-retest reliability was implemented using 10 additional high school teachers who completed the survey twice, four weeks apart. The responses on both surveys were compared to measure consistency in answers. Pearson correlations were calculated to be .914 , coefficients sufficient enough to proceed with the study.

The 26-item questionnaire included general teacher demographic questions followed by statements on each instructional practices using a 4-point Likert-scale that ranged from 1 = Never; 2 = Rarely; $3=$ Frequently; to $4=$ Daily. The 4-point scale required the teachers to take a stance on their reported use of any instructional practice, and avoided a neutral response towards the instructional practice in question. This allowed the researcher to better identify a relationship, if one existed. Of the 26 items included on the questionnaire, 20 statements address the variables of graphic organizers (e.g., I use visual displays to reinforce learning), mnemonic strategies (e.g., I use 
acronyms to help students remember key concepts), peer-mediated activities (e.g., I use peer tutoring during the instructional block), activating knowledge (e.g., I activate student background knowledge before introducing a new concept), activity-based learning (e.g., my students use hands-on activities more than text-based learning), study aids (e.g., I provide guided notes to students for class lectures/discussions), strategy instruction (e.g., I teach test-taking strategies/skills to my students), explicit instruction (e.g., my instruction is highly organized and task oriented), technology-based practices (e.g., I integrate technology based lessons into the curriculum), and culturally responsive teaching (e.g., I teach with the cultural background of my students in mind).

Participants had the opportunity to describe or provide examples of their response to each statement on the survey. Each instructional best practice/variable was represented in at least two separate survey items to address each strategy in different ways. The responses to the items were regrouped to confirm participants' belief of each variable. In addition, the survey includes open-ended questions at the end for the participants to add any additional information on the instructional practices they used during the 2010-2011 school year. This was intended to provide the researcher with a better understanding of the practices used in each educational placement.

\section{Procedures}

An approved proposal for this dissertation project was submitted to the MiamiDade County Public School Office of Program Evaluation as well as Florida International University's Office of Research Integrity for Institutional Review Board (IRB) approval to conduct research in a school setting. Once approval was granted, an information request was submitted to MDCPS to obtain data on all $8^{\text {th }}$ grade, Black students with 
SLD within the district; that is, their reading and math achievement scale scores for 20092010, their gender, their time with nondisabled peers, their school location, their class schedule as well as their educational placement for the current school year.

Once data were received, each student's records were reviewed to determine if his or her school location and placement status met the criteria for this study. Any students attending center schools, charter schools, or alternative education schools were not included. Additionally, both math and reading instruction must have occurred in the same placement for the 2010-2011 school year. Students who received language arts instruction in a different placement than their math instruction were excluded from the sample. For example, if a student was in the resource room for language arts but received math instruction in an inclusive classroom, he or she was not included in the sample.

\section{Achievement Gains}

The identified students were further examined to determine which students had a standardized state assessment score for the 2009-2010 FCAT. This procedure excluded those students receiving modified or alternative curriculum and taking the alternate assessment. These data were neither created nor manipulated; archival data was used. Once the students were identified and descriptive statistics were recorded, their achievement gains were inputted into an Excel file. Achievement indicators for this study included:

1. The students' 2009-2010 and 2010-2011 scale scores for the FCAT-SSS reading test.

2. The students' 2009-2010 and 2010-2011 scale scores for the FCAT-SSS mathematics test. 


\section{Instructional Practices}

The Teacher Instructional Practices Survey (see Appendix A) was used to collect data on the reported use of instructional best practices in each educational placement during the 2010-2011 year. Student records indicated placement and identified the teachers for math and language arts classes. An introductory email was sent to 238 identified teachers describing and explaining the purpose of the study and encouraging them to complete the survey included in the email. The email also included a research information letter explaining the purpose of the study, assurance of confidentiality, expectations for both the researcher and participant, and contact information for the university and researcher. Teachers were notified in the email that they would also receive the survey with attachments at their school site via mail; the mailed surveys included a preaddressed, stamped envelope for participants to return the completed surveys to the researcher. Teachers that choose to participate had the option of completing and returning the survey via U.S. mail or electronically.

To increase the rate of response, a follow-up email was sent 5 days later encouraging teachers to complete the survey. This occurred at the end of the 2010-2011 school year. For teachers who did not respond, the survey was sent again via U.S. mail and email at the beginning of the 2011-2012 school year. The researcher expected to have a survey returned from a corresponding teacher for every student. It should be noted that more than one student had the same teacher for language arts and math, especially in the resource placements. Of the 238 teachers invited to participate in the study, 36 teachers returned a completed survey; this represents a $15.13 \%$ return rate. 
All possible measures were taken to protect the confidentiality of each student and teacher involved in the study. A numerical code was used to identify each student and survey when documenting achievement gains and reported use of instructional best practices. Original documents were secured in a locked filing cabinet of a home office that can only be accessed by the researcher. The documents will be kept for 3 years from the completion of the study and destroyed after that time frame.

\section{Data Analysis}

All of the collected data for each variable were entered into the SPSS database for analysis using a combination of statistical techniques. Descriptive statistics were used to summarize student achievement, demographic and survey data, including means and standard deviations of groups in the sample. The statistical significance of the proposed relationships in the hypotheses was measured using the $\mathrm{F}$ test because it is very robust; therefore, the assumptions of normal distribution of the variables and random selection of subjects can be violated without doing significant harm to the procedure (Newman et al., 2006).

The responses to the open-ended questions supplemented the data collected to address the relationship between the educational placement of Black students with SLD and the reported use of instructional best practices as indicated in the third research question. For example, an inclusion or resource teacher could have described a particular strategy/instructional method used that was not included among the ten indicators of instructional best practices selected for this study. That additional information was relevant to the relationship in question. All responses to each open ended questions were listed by subject area (reading and math) and teacher role (general and special educator). 
Each list was reviewed for common topics and coding categories were created (Bogdan \& Biklen, 2007).

The mean results for each variable in the survey were compared to the educational placement and achievement gains of the students included in the sample to help identify if any statistically significant linear relationships exist between specific variables.

The magnitude of the relationships between educational placement, achievement gains, and instructional best practices was measured using the Pearson product-moment correlation coefficient using two-tailed tests where the direction of the correlation is uncertain. The Pearson product-moment correlation coefficient indicates the direction and strength of the relationship between multiple variables simultaneously (Hinkle, Wiersma, \& Jurs, 2003). The Bonferroni method was used to control for Type 1 error buildup (Newman, Fraas, \& Laux, 2000). An alpha level of .05 was used to determine significance of relationships with a $95 \%$ confidence level; the costs of rejecting the research hypothesis in error were not so serious as to justify a more strict confidence level.

Multiple linear regression was used to determine which variables accounted for unique variance in predicting the criterion variable when controlling for other variables (Newman \& McNeil, 1998). The models that reflect the research questions can be written out when using multiple linear regressions. Furthermore, multiple linear regressions lends itself to test relationships between continuous variables, between categorical variables, or between categorical and continuous variables (McNeil et al., 1996). In this study, the continuous variable was the FCAT scale scores and educational placement was a categorical variable. The open-ended survey questions were reviewed individually coding 
categories were created to supplement the quantitative data collected (Bogdan \& Biklen, 2007) to address the relationship between the educational placement of Black students with SLD and the reported use of instructional best practices as indicated in the third research question.

\section{Chapter Summary}

This chapter presented the methodology chosen for this research study. An ex post facto research design was used to examine educational placement, instructional best practices, and achievement gains of Black students with specific learning disabilities in urban secondary settings. The researcher investigated whether Black students with SLD serviced in inclusive content area courses demonstrate a difference in achievement gains when compared to Black students with SLD serviced in resource classes and the relationship to the reported use of instructional best practices.

The setting of the study occurred within the Miami-Dade County Public School District, the fourth largest school district in the nation. Participants for this study included a sample size of 314 eighth grade black students with specific learning disabilities and 36 respective teachers for math and language arts instruction. The Teacher Instructional Practices Survey was used to collect data on the instructional practices within each educational placement. All demographic, achievement, and survey data were collected and inputted into an SPSS data file for analysis. Statistical procedures for data analysis included $\mathrm{F}$ tests and two-tailed, non-directional tests using multiple linear regressions.

The information learned from this study adds to the existing literature on inclusive education and achievement as it focused on Black students with specific learning disabilities in urban settings at the secondary level. This expanded the studies conducted 
on this topic and may be used to assist decision makers with where and how these students are best educated. 


\section{Chapter IV}

\section{RESULTS}

This study examined the relationship between inclusive and resource educational placement, instructional best practices, and the academic achievement of Black students with specific learning disabilities. This study sought to determine whether Black students with SLD in urban secondary school settings serviced in inclusive language arts and math classes demonstrate a difference in achievement gains as evidenced by growth in scale scores when compared to Black students with SLD serviced in resource language arts and math classes. In addition, this study investigated the relationship between the reported use of instructional best practices and achievement gains with this population of students while taking into account their educational placement. The results of this study are presented in this chapter. The student demographic and survey descriptive statistics are presented first, followed by the inferential statistics presented by each research question.

\section{Student Demographic Descriptive Statistics}

The minimum and maximum FCAT scores of each test and overall gains for each subject area are provided in Table 3 as well as the means and standard deviations. The mean FCAT score for both 2011 reading and math are higher than the 2010 scores. Additionally, the mean math gains are higher than the mean reading gains. The minimum scores for both math and reading gains are negative numbers, indicating some student scores dropped from 2010 to 2011 . Out of a possible 500 points, the average 2011 score for this sample in math was 265 and 244 in reading. 
Table 3

Descriptive Statistics for Student FCAT Scores $(N=314)$

\begin{tabular}{lrrrr}
\hline Scale Score & Minimum & Maximum & Mean & Std. Deviation \\
\hline 2010 Math & 100 & 386 & 228.07 & 64.71 \\
2011 Math & 100 & 371 & 265.02 & 49.12 \\
Math Gains & -142 & 204 & 36.95 & 55.95 \\
2010 Reading & 100 & 363 & 240.61 & 58.52 \\
2011 Reading & 100 & 350 & 243.75 & 50.75 \\
Reading Gains & -127 & 145 & 3.13 & 45.54 \\
\hline
\end{tabular}

\section{Teacher Survey Descriptive Statistics}

The minimum and maximum scores are provided in Table 4 as well as the means and standard deviations of each instructional practice measured in reading from part II of the survey; the scale ranged from $1-4$. The 22 surveys in reading provided data for 56 students included in the sample. Peer-mediated activities had the lowest and explicit instruction had the highest mean score for reading.

The minimum and maximum scores are provided in Table 5 as well as the means and standard deviations of each instructional practice measured in math from part II of the survey. The 14 surveys in math provided data for 35 students included in the sample. Technology-based practices had the lowest and explicit instruction had the highest mean score for math. 
Table 4

Descriptive Statistics for Instructional Best Practices: Reading $(N=56)$

\begin{tabular}{lrrrr}
\hline Reading & Minimum & Maximum & Mean & $\begin{array}{c}\text { Std. } \\
\text { Deviation }\end{array}$ \\
\hline Graphic Organizers & 2.0 & 4.0 & 3.18 & .34 \\
Mnemonic Strategies & 1.5 & 3.5 & 2.76 & .55 \\
Peer-Mediated Activities & 2.0 & 4.0 & 2.67 & .62 \\
Study Aids & 1.5 & 4.0 & 2.88 & .62 \\
Activating Knowledge & 2.0 & 4.0 & 3.26 & .49 \\
Activity-based Learning & 2.0 & 3.5 & 2.96 & .37 \\
Strategy Instruction & 2.5 & 4.0 & 3.38 & .43 \\
Explicit Instruction & 3.0 & 4.0 & 3.78 & .32 \\
Technology-based Practices & 1.0 & 4.0 & 2.68 & .75 \\
Culturally Responsive Teaching & 2.5 & 4.0 & 3.37 & .54 \\
\hline
\end{tabular}

Table 5

Descriptive Statistics for Instructional Best Practices: Math $(N=35)$

\begin{tabular}{lrrrr}
\hline Math & Minimum & Maximum & Mean & $\begin{array}{c}\text { Std. } \\
\text { Deviation }\end{array}$ \\
\hline Graphic Organizers & 2.5 & 4.0 & 3.12 & .41 \\
Mnemonic Strategies & 2.0 & 4.0 & 3.06 & .42 \\
Peer-Mediated Activities & 1.5 & 3.5 & 2.67 & .65 \\
Study Aids & 1.5 & 3.5 & 2.80 & .58 \\
Activating Knowledge & 2.0 & 4.0 & 3.06 & .43 \\
Activity-based Learning & 2.0 & 3.5 & 2.69 & .37 \\
Strategy Instruction & 2.5 & 4.0 & 3.30 & .39 \\
Explicit Instruction & 3.0 & 4.0 & 3.61 & .30 \\
Technology-based Practices & 1.0 & 4.0 & 2.66 & .57 \\
Culturally Responsive Teaching & 2.0 & 4.0 & 2.97 & .47 \\
\hline
\end{tabular}




\section{Open-Ended Survey Items}

Open-ended survey items were incorporated into part III of the survey. All responses to each open ended question were listed by subject area (reading and math) and teacher role (general and special educator). Each list was reviewed for common topics and coding categories were created. The coding categories are presented in alphabetical order and include some of the best practices identified for this study.

\section{Question 24}

List any additional instructional practices/strategies you implemented and indicate how often you used them.

Participants were provided the opportunity to describe any additional instructional practices/strategies. Teacher responses did not indicate how often they used the instructional practice/strategy. Table 6 indicates the coding categories in reading identified for this question. General educators identified more instructional best practices than special educators; both identified strategy instruction and commercial programs as additional practices/strategies they implemented for reading during the 2010-2011 school

year. CRISS (Creating Independence through Student-owned Strategies) is a professional development program that teaches students how to learn and fits into the existing school curricula (Santa, Havens, \& Valdes, 2007).

Table 7 indicates the coding categories in math identified for this question. Both special and general educators identified activity-based learning, peer-mediated activities, technology-based practices and review strategies as additional practices/strategies they implemented for math during the 2010-2011 school year. 
Table 6

Question 24: Additional Instructional Practices in Reading

\begin{tabular}{lcc}
\hline & \multicolumn{2}{c}{ Educators } \\
\cline { 2 - 3 } Instructional Practice & Special & General \\
\hline Activating knowledge* & & $\mathrm{Y}$ \\
Activity-based learning* & $\mathrm{Y}$ & $\mathrm{Y}$ \\
Commercial programs (e.g., CRISS strategies) & & $\mathrm{Y}$ \\
Graphic organizers* & $\mathrm{Y}$ & \\
Multisensory & & $\mathrm{Y}$ \\
Oral-based practices (e.g., think aloud modeling) & & $\mathrm{Y}$ \\
Peer-mediated activities* & $\mathrm{Y}$ \\
Strategy instruction* & & $\mathrm{Y}$ \\
Text-based practices (e.g., text mapping) & & \\
\hline
\end{tabular}

Notes. *Instructional best practice as identified for this study.

Y stands for "Yes"; this group reported using the practice.

Table 7

Question 24: Additional Instructional Practices in Math

\begin{tabular}{lcc}
\hline & \multicolumn{2}{c}{ Educators } \\
\cline { 2 - 3 } Instructional Practice & Special & General \\
\hline Activity-based learning* & $\mathrm{Y}$ & $\mathrm{Y}$ \\
Differentiation (e.g., differentiate instruction) & $\mathrm{Y}$ & \\
Explicit instruction* & $\mathrm{Y}$ & $\mathrm{Y}$ \\
Peer-mediated activities* & $\mathrm{Y}$ & $\mathrm{Y}$ \\
Review strategies (e.g., review concepts) & & $\mathrm{Y}$ \\
Structure (e.g., using structured activities) & & $\mathrm{Y}$ \\
Study aids* & & $\mathrm{Y}$ \\
Technology-based practices* & & \\
\hline
\end{tabular}

Notes. *Instructional best practice as identified for this study.

Y stands for "Yes"; this group reported using the practice. 


\section{Question 25}

Describe, in detail, what you believe to be the most effective instructional strategy/practice for students with disabilities in your subject area(s) and why.

Participants were provided the opportunity to state what they believed to be the most effective instructional strategy/practice for students with disabilities. None of the responses included a statement explaining why they believed an instructional strategy/practice to be most effective. Table 8 indicates the coding categories in reading identified for this question. Both special and general educators identified graphic organizers, peer-mediated activities, and differentiation as the most effective instructional strategy/practice for students with disabilities in reading.

\section{Table 8}

Question 25: Most Effective Practice for SWD in Reading

\begin{tabular}{lcc}
\hline & \multicolumn{2}{c}{ Educators } \\
\cline { 2 - 3 } Instructional Practice & Special & General \\
\hline Activity-based learning* & $\mathrm{Y}$ \\
Differentiation (e.g., differentiate instruction) & $\mathrm{Y}$ & $\mathrm{Y}$ \\
Explicit instruction* & $\mathrm{Y}$ & $\mathrm{Y}$ \\
Graphic organizers* & $\mathrm{Y}$ & \\
Modeling & $\mathrm{Y}$ & $\mathrm{Y}$ \\
Peer-mediated activities* & $\mathrm{Y}$ & \\
Review strategies (e.g., repetition) & & $\mathrm{Y}$ \\
Structure (e.g., using co-teachers) & & $\mathrm{Y}$ \\
Time factors (e.g., provide additional time) & & \\
\hline
\end{tabular}

Notes. *Instructional best practice as identified for this study.

Y stands for "Yes"; this group reported using the practice.

Table 9 indicates the coding categories in math identified for this question. Both special and general educators identified peer-mediated activities, differentiation, and 
review strategies as the most effective instructional strategy/practice for students with disabilities in math.

Table 9

Question 25: Most Effective Practice for SWD in Math

\begin{tabular}{lcc}
\hline & \multicolumn{2}{c}{ Educators } \\
\cline { 2 - 3 } Instructional Practice & Special & General \\
\hline Accommodations (e.g., shorten assignments) & $\mathrm{Y}$ \\
Activity-based learning* & & $\mathrm{Y}$ \\
Behavior strategies (e.g., positive reinforcement) & $\mathrm{Y}$ \\
Differentiation (e.g., individualized reteaching) & & $\mathrm{Y}$ \\
Graphic organizers* & $\mathrm{Y}$ & $\mathrm{Y}$ \\
Peer-mediated activities* & $\mathrm{Y}$ \\
Review strategies (e.g., repetition) & $\mathrm{Y}$ & $\mathrm{Y}$ \\
\hline
\end{tabular}

Notes. *Instructional best practice as identified for this study.

Y stands for "Yes"; this group reported using the practice.

\section{Question 26}

Is there anything else you would like to add about the instructional practices you used during the 2010-2011 school year?

Participants were provided the opportunity to add any further information on the instructional practices used during the 2010-2011 school year. Table 10 indicates the coding categories in reading. Both general and special educators included teacher factors as additional practices used during the 2010-2011 school year. Table 11 indicates the coding categories in math identified for this question. Special and general educators did not share any common categories. 
Table 10

Question 26: Additional Information in Reading

\begin{tabular}{lcc}
\hline & \multicolumn{2}{c}{ Educators } \\
\cline { 2 - 3 } Instructional Practice & Special & General \\
\hline Activating knowledge* & $\mathrm{Y}$ & \\
Class composition (e.g., multi-grade levels) & & $\mathrm{Y}$ \\
Data-based practices (e.g., data-driven instruction) & & $\mathrm{Y}$ \\
Motivation (e.g., motivating students to learn) & $\mathrm{Y}$ & \\
Processing information (e.g., wait time) & $\mathrm{Y}$ \\
Review strategies (e.g., repetition/review) & & $\mathrm{Y}$ \\
Strategy instruction* & $\mathrm{Y}$ \\
Teacher factors (e.g., teacher consistency) & & $\mathrm{Y}$ \\
Technology-based practices* & & $\mathrm{Y}$ \\
\hline
\end{tabular}

Notes. *Instructional best practice as identified for this study.

Y stands for "Yes"; this group reported using the practice.

Table 11

Question 26: Additional Information in Math

\begin{tabular}{lcc}
\hline & \multicolumn{2}{c}{ Educators } \\
\cline { 2 - 3 } Instructional Practice & Special & General \\
\hline Activating knowledge* & & $\mathrm{Y}$ \\
Curriculum (e.g., new math curriculum) & $\mathrm{Y}$ \\
Differentiation (e.g., using learning styles) & $\mathrm{Y}$ \\
Obstacles (e.g., lack of technology) & $\mathrm{Y}$ \\
Time factors (e.g., time needed to master concepts) & \\
\hline
\end{tabular}

Notes. *Instructional best practice as identified for this study.

Y stands for "Yes"; this group reported using the practice.

\section{Inferential Statistics}

For each research question, the hypotheses presented in Chapter 3 are analyzed using statistical procedures including the F test and the Pearson product-moment correlation coefficient. The results are presented in this section. 


\section{Research Question 1}

The first research hypothesis states that there is a significant difference in math achievement gains of Black students with SLD serviced in secondary resource settings as compared to inclusive educational classroom placements. The first alternative hypothesis states that there is a significant difference in math achievement gains when controlling for gender. An F test was conducted to answer this research question. The test was significant at .002 when controlling for gender. The educational placement variable accounted for significant variance of the math gains for resource placement. The results indicate that those students serviced in resource educational classroom placements had significantly greater achievement gains in math when controlling for gender. There was a small effect size, $\mathrm{R}^{2}=.037$, for the relationship between math gains and educational placement. The results are illustrated in Table 12 and Table 13.

Table 12

Model Summary of Educational Placement and Math Gains (N=314)

\begin{tabular}{ccccc}
\hline R & R square & Adjusted R Square & F & Significance \\
\hline .193 & .037 & .031 & 6.007 & .003 \\
\hline
\end{tabular}

Table 13

Coefficients: Educational Placement and Math Gains (N=314)

\begin{tabular}{lcccc}
\hline Variable & $B$ & $t$ & $p$ & Sig. \\
\hline Educational Placement & 19.141 & 3.065 & .002 & $* *$ \\
Gender & -9.098 & -1.351 & .178 & \\
\hline Note. ${ }^{* *} p \leq .01$ and significant at the .01 alpha level. & & &
\end{tabular}




\section{Research Question 2}

The second research hypothesis states that there is a significant difference in reading achievement gains of Black students with SLD serviced in secondary resource settings as compared to inclusive educational classroom placements. The second alternative hypothesis states that there is a significant difference in reading achievement gains when controlling for gender. An F test was conducted to answer this research question. The results indicate that there was no significant difference in the reading achievement gains for this sample population. The results are illustrated in Table 14. Table 14

Model Summary of Educational Placement and Reading Gains (N=314)

\begin{tabular}{ccccc}
\hline $\mathrm{R}$ & $\mathrm{R}$ square & Adjusted R Square & $\mathrm{F}$ & Significance \\
\hline .126 & .016 & .010 & 2.513 & .083 \\
\hline
\end{tabular}

\section{Research Question 3}

The third research hypothesis states that there is a relationship between the educational placement of Black students with SLD and the reported use of instructional best practices. A Pearson product-moment correlation coefficient was conducted to answer this research question for both reading and math while controlling for Type 1 error buildup using the Bonferroni method. The variable found to be significantly correlated with educational placement (EPL) for reading was strategy instruction. Strategy instruction was negatively correlated with educational placement, meaning the higher scores were with inclusive placement. The correlation was significant at the .01 level (2-tailed). Results for reading are illustrated in Table 15. 
Table 15

Educational Placement and Instructional Best Practices: Reading

\begin{tabular}{llr}
\hline Instructional Best Practice & & Educational Placement \\
\hline Graphic Organizers & Pearson Correlation & .033 \\
& Sig. (2-tailed) & .810 \\
Mnemonic Strategies & Pearson Correlation & .235 \\
& Sig. (2-tailed) & .081 \\
Peer-Mediated Activities & Pearson Correlation & .028 \\
& Sig. (2-tailed) & .839 \\
Study Aids & Pearson Correlation & .068 \\
& Sig. (2-tailed) & .618 \\
Activating Knowledge & Pearson Correlation & .067 \\
Activity-Based Learning & Sig. (2-tailed) & .626 \\
Strategy Instruction & Pearson Correlation & .120 \\
& Sig. (2-tailed) & .378 \\
Explicit Instruction & Pearson Correlation & $* .382$ \\
& Sig. (2-tailed) & .004 \\
Technology-Based Practices & Pearson Correlation & -.243 \\
& Sig. (2-tailed) & .071 \\
Culturally Responsive Teaching & Pearson Correlation & .348 \\
& Sig. (2-tailed) & .009 \\
& Pearson Correlation & .065 \\
& Sig. (2-tailed) & .636 \\
\hline
\end{tabular}

Note. $* p \leq .005$ and correlation is significant at the 0.005 level (2-tailed).

The variable found to be significantly correlated with educational placement (EPL) for math was graphic organizers. Graphic organizers were significant at the .01 alpha level and was positively correlated with educational placement, meaning the higher scores were with resource placements. The other instructional practices showed no significant correlation. The results for math are illustrated in Table 16. 
Table 16

Educational Placement and Instructional Best Practices: Math

\begin{tabular}{llr}
\hline Instructional Best Practice & & Educational Placement \\
\hline Graphic Organizers & Pearson Correlation & $* .523$ \\
Mnemonic Strategies & Sig. (2-tailed) & .001 \\
& Pearson Correlation & -.143 \\
Peer-Mediated Activities & Sig. (2-tailed) & .411 \\
& Pearson Correlation & .170 \\
Study Aids & Sig. (2-tailed) & .328 \\
& Pearson Correlation & -.387 \\
Activating Knowledge & Sig. (2-tailed) & .022 \\
& Pearson Correlation & .264 \\
Activity-Based Learning & Sig. (2-tailed) & .126 \\
Strategy Instruction & Pearson Correlation & .184 \\
& Sig. (2-tailed) & .291 \\
Explicit Instruction & Pearson Correlation & -.434 \\
& Sig. (2-tailed) & .009 \\
Technology-Based Practices & Pearson Correlation & .183 \\
Culturally Responsive Teaching & Sig. (2-tailed) & .293 \\
& Pearson Correlation & .274 \\
\hline Note. $* p \leq .005$ and correlation is significant at the 0.005 level (2-tailed). & .111 \\
& Sig. (2-tailed) & .064 \\
& Pearson Correlation & .716 \\
\hline
\end{tabular}

\section{Research Question 4}

The fourth research hypothesis states that there is a relationship between the reading achievement gains of Black students with SLD and the reported use of instructional best practices. The alternative hypothesis states that there is a relationship between the reading achievement gains when controlling for gender. An F test was conducted to answer this research question. The results indicate that there was no significant relationship between reading achievement gains and the reported use of any of the instructional best practices. The results are illustrated in Table 17. 
Table 17

Model Summary of Instructional Best Practices and Reading Gains $(N=56)$

\begin{tabular}{ccccc}
\hline $\mathrm{R}$ & R square & Adjusted R Square & F & Significance \\
\hline .260 & .067 & -.166 & .289 & .985 \\
\hline
\end{tabular}

\section{Research Question 5}

The fifth research hypothesis states that there is a relationship between the math achievement gains of Black students with SLD and the reported use of instructional best practices. The alternative hypothesis states that there is a relationship between the math achievement gains when controlling for gender. An F test was conducted to answer this research question. The results indicate that there was no significant relationship between the math achievement gains and the use of any of the instructional best practices for this population. The results are illustrated in Table 18.

Table 18

Model Summary of Instructional Best Practices and Math Gains $(N=35)$

\begin{tabular}{ccccc}
\hline R & R square & Adjusted R Square & F & Significance \\
\hline .360 & .129 & -.287 & .310 & .976 \\
\hline
\end{tabular}

\section{Chapter Summary}

This chapter delineated the results of the study including the descriptive statistics of the student demographics and teacher surveys. The responses of the open-ended survey items were also analyzed and categorized into themes. The inferential statistics included the results of each research question.

Results indicate that there was a significant difference in math gains but no significant difference in reading gains of Black students with SLD serviced in secondary 
inclusive settings as compared to resource settings. Also, there was no significant relationship between math or reading achievement gains and the use of instructional best practices. However, when looking at reading instruction, there was a relationship between inclusive placement and the use of strategy instruction. For math instruction, there was a relationship between resource placement and the use of graphic organizers. The results of this study are discussed in Chapter 5 . 


\section{Chapter V}

\section{DISCUSSION}

This chapter discusses the conclusions derived from the results of this study. First presented is a brief overview of the study including a summary of the results followed by a discussion with respect to the relevant literature. Lastly, this study's limitations, implications for practice, and suggestions for further research are discussed.

This study examined the relationship between inclusive and resource educational placement, instructional best practices, and the academic achievement of Black students with specific learning disabilities. This study sought to determine whether Black students with SLD in urban secondary school settings serviced in inclusive language arts and math classes demonstrate a difference in achievement gains as evidenced by growth in scale scores when compared to Black students with SLD serviced in resource language arts and math classes. In addition, this study investigated the relationship between the reported use of instructional best practices and achievement gains with this population of students while taking into account their educational placement. Achievement data for 314 students were collected and analyzed along with corresponding teacher survey data.

Results indicate no significant difference in reading but a significant difference in math gains of students served in inclusive settings as compared to resource settings with a small effect size. Also, no significant relationship was found between achievement gains and the reported use of instructional best practices. However, there was a relationship between educational placement and the use of instructional best practices.

Approximately $52.2 \%$ of the Black students with SLD identified for this study were in a more restrictive, segregated setting for both language arts and math instruction. 
This was aligned with the research that indicated Black students with disabilities are more likely to be underrepresented in general education settings and overrepresented in more restrictive settings (Blanchett, 2009; Skiba et al., 2006). The data from this student sample contrasts with some of the key findings from the National Center for Special Education Research. In their study of secondary students with learning disabilities and their experiences in general education, they found that students with learning disabilities are equally likely to have language arts in special and general education settings, and are more likely to take math in general education (Newman, 2006). Over half of the sample of Black students with SLD in this study had both math and reading in a special education classroom setting.

The student descriptive statistics results of this study reveal negative minimum scores for both math (-142) and reading (-127) gains, indicating student scores dropped from 2010 to 2011. Out of a total possible score of 500, the average 2011 score for this sample in math was 265 and 244 in reading. Although both NCLB (2002) and IDEA (2004) hold high expectations for academic performance of students with disabilities, the sample of Black students with SLD in this study did not demonstrate high academic performance in either math or reading. The scores of this sample may reflect that Black students with disabilities in urban settings continue to struggle when it comes to receiving quality instruction (Blanchett, Klingner, \& Harry, 2009). In addition to the experiences associated with attending urban schools, these students also experience the inequalities of the special education system (Blanchett, 2009). 


\section{Achievement Gains and Educational Placement}

The research hypothesis that there is a significant difference in math achievement gains of Black students with SLD serviced in secondary resource settings as compared to inclusive educational classroom placements when controlling for gender was supported by the results of this study. Students in resource placements had significantly greater math achievement gains than those students in inclusive placements. However, these results should be viewed with caution as there was a small effect size for this test.

As the findings from Berry (2003) suggest, this sample may have received math instruction in the resource setting based on NCTM standards which encompasses the learning styles and cultural preferences of Black students resulting in a positive influence on math achievement of this sample population. Another possible explanation for the results may be that students in resource settings had a lower beginning score (PreMTH) than those in inclusive classes for math instruction. This would have allowed for more growth from one year to the next. Also, there may be more specialized, individual instruction in the separate setting for math instruction.

However, the hypothesis for reading achievement gains was not supported by the results of this study. There was no significant difference in the reading achievement gains for this sample population. These results may be due to the fact that in some cases, students at the same school yet in different classroom placements had the same teacher for math and/or language arts instruction. So there is a possibility that there was no distinction in instruction from one educational placement to another, resulting in no significant difference in reading achievement gains for this sample population. Fore, et al. (2008) also found no significant evidence to indicate varied achievement based on 
placement. This is similar to the results of this study for reading achievement where no significant difference was indicated between students in resource as compared to inclusive classroom placements.

Results for both math and reading achievement gains and educational placement contrast with research that suggests more inclusive placements are linked to performance on eighth grade state level assessments for students with disabilities (Luster \& Durrett, 2003). Although the results contradicted earlier findings, no information was gathered in this study about the types of inclusive classrooms used for placement. Consequently, the findings do not strongly support a more restrictive setting.

\section{Educational Placement and Instructional Best Practices}

Results did indicate a relationship between the educational placement of students and the reported use of two of the instructional best practices. For reading, strategy instruction was correlated to inclusive placements. For math, graphic organizers were correlated to resource placements. For the sample in this study, this means that the language arts inclusion teachers reportedly employed instruction that involved teaching students learning strategies or as Bost and Riccomini (2006) explain it, teaching students how to learn. The resource math teachers reported using visual representations that made relationships between concepts and related facts more apparent and arranges information in a way that facilitates learning (Anderson et al., 2004; Scruggs et al., 2010). Hughes, Maccini, and Gagnon (2003) identified strategy instruction as student-focused and graphic organizers as teacher-focused interventions. It may mean that the language arts inclusion teachers in this study were more student-focused and the math resource teachers were more teacher-focused in their use of strategies with this sample population. 
These results may be due to the emphasis of the use of strategies to support the standard curriculum and to prepare students for standardized tests. This emphasis is evident in the district's professional development targeting teachers of the core curriculum. Therefore, teachers in inclusive settings may be likely to use strategy instruction more often than special educators. Also, special educators may be more likely to use visuals to reinforce instruction for students with disabilities as the use of graphic organizers are emphasized to address the diverse needs typically displayed in resource settings.

\section{Achievement Gains and Instructional Best Practices}

The research hypotheses that there is a relationship between both math and reading achievement gains of the students in this sample and the reported use of instructional best practices when controlling for gender was not supported by the results of this study. Although strategy instruction was found to be correlated to inclusive placement for reading, the achievement gains in this study contrasted with the research. Carter et al. (2005) actually saw increases in test performance of secondary students with high-incidence disabilities that received strategy instruction in test-taking skills. This could be the effect of having only 36 teachers return a completed survey; this represents a $15.13 \%$ return rate. The low number of returned surveys may have resulted in a poor data analysis. Results may have been different had the survey return rate been higher.

Although no relationship was found in this study between achievement gains and instructional best practices, other factors may have played a role in achievement gains with this sample population. The theory emerging from Pressley, Raphael, and Gallagher (2004) was that high achievement for urban, Black students was caused by multiple 
factors including strong leadership, accountability, and academic focus. Individual-level predictors, such as student effort and associations with positive peers, have also played a substantial role in increasing Black student achievement (Stewart, 2007). Mayer and Tucker (2010) identified key factors to promote high achievement for students of color which included appropriate scaffolding and close monitoring of students' social and academic growth.

In the school district for this sample population, students struggling in reading and/or math at the secondary level (as indicated by standardized test scores) are required to take a second course of reading and/or math instruction. The courses are considered intensive and are taken in addition to the standard core curriculum course in which all students are enrolled. As such, if any of the students in this sample population were taking two courses of reading and/or math instruction, it could also have been a factor in the achievement gains from one year to the next.

\section{Open-Ended Survey Responses}

An analysis of the open-ended questions included on the survey identified coding categories relative to instructional best practices used in both resource and inclusive educational placements. Special and general educators reported a variety of practices used in their instruction. Although some participants mentioned the use of identified best practices from the study, some responses did include practices not identified as one of the ten instructional best practices for this study. This could mean that teachers reported using what they are comfortable with (i.e. multisensory) or used what they were told to use by their school (i.e. differentiation, commercial programs) instead of what research indicated as best practices. Review strategies were one category that both general and 
special education teachers often discussed in their responses. This may indicate that teachers felt it necessary to consistently review, practice, and provide repetition for students with disabilities to learn the content. There was no definition of what the researcher meant by instructional practices and this may have led teachers to misuse the term or only rely on what they believed to be an instructional practice.

Several of the practices identified by the teachers in this study aligned with the literature on instructional best practices for secondary students with disabilities. Peermediated activities (Anderson et al., 2004; Hughes et al., 2003; Scruggs et al., 2010), activity-based learning (Anderson et al., 2004; Scruggs et al., 2010), graphic organizers (Anderson et al., 2004; Hughes et al., 2003; Scruggs et al., 2010), and explicit instruction (Bost \& Riccomini, 2006; Scruggs et al., 2010) were identified in the literature and discussed in the open-ended survey question regarding the most effective practices for SWD. Teachers in this study are reportedly implementing some of the best practices for instruction for this sample population of students. Results from this study revealed that explicit instruction had the highest mean score of all the instructional best practices for both math and reading. Overall, general educators reported using more research-based instructional practices than did special educators.

Mnemonic strategies was not reported by the teachers in this study even though the findings of Wolgemuth, Cobb, and Alwell (2008) strongly support the use of this strategy in the improvement of academic performance across study methods, student ages, disabilities, and educational settings. The research is clear that when ethnically diverse students are taught through their own cultural filters, their academic achievement improves (Gay, 2004). However, just like mnemonic strategies, none of the teachers in 
this study included CRT practices in their responses. It could be that teachers were unaware that CRT is an effective instructional practice that takes into account a student's cultural characteristics and experiences as channels for effective teaching (Gay, 2002b) even if they are implementing some of the tenets. Increasing academic achievement is possibly the most important goal of CRT (Howard, 2003) and without it learning can never be optimal for this student sample population (Gay, 2002a).

\section{Implications for Practice}

The results of this study have important implications for current practice. The literature reviewed identified instructional best practices utilized for secondary students with disabilities. The statistical analysis in this study found a correlation between the use of just two instructional best practices and the educational placement of students for reading and math. This implies that professional development may be necessary for both special and general educators in urban settings. Having teachers trained on researchbased instructional best practices to use for students with disabilities in urban secondary settings would support learning in both academic areas as supported by research.

Additionally, IEP teams should consider general education as the least restrictive environment for Language Arts/Reading instruction for Black students with disabilities in urban secondary settings. The results of this study indicate no difference in reading achievement gains for students in either educational placement. This may imply that no specialized instruction is taking place in resource classrooms to indicate the need for a

more restrictive setting. IEP teams may also want to consider the instructional practices taking place and the supports available to students within in each educational placement prior to making placement decisions for this population of students with disabilities. With 
"educational benefit" as the standard for responsible inclusion, the focus should be placement for instruction rather than physical location of the instruction (Hagan-Burke \& Jefferson, 2002).

\section{Limitations}

Limitations of this study should be noted. The survey instrument was the primary means of collecting data on the reported use of instructional best practices in each educational placement setting. Data were collected and analyzed on a total of 36 surveys; this represents a $15.13 \%$ return rate. The 36 surveys yielded data for only 78 of the 314 identified students for the study. Therefore, all analyses involving instructional best practices were limited to $24.84 \%$ of the sample student population. Additionally, classroom observations were not utilized to gather data on instructional best practices; this limited the amount of data that could be used to analyze teachers' use of the instructional best practices.

Second, the survey included open-ended questions that provided additional information as it relates to instructional best practices. However, not every participant provided a response to these questions and the responses varied in length. Since the survey was not completed in the presence of the researcher, follow up questions were not utilized to expand on the original answers; this would have strengthened the study as teachers would have been able to clarify or explain their responses. Also, the identified best practices were not defined on the actual survey. Therefore, teachers completing the survey did not have a description of each practice to assist them with the open-ended questions. 
Third, it should be noted that some of the identified teachers provided instruction in both inclusive and resource classroom placements. This may be due to changes in teacher certification rules for special educators. That is, teachers already certified in special education are now required to also be certified in the content area that they teach. Teachers are then qualified to teach general and/or special education courses. For this study, some teachers were providing instruction in both settings. Therefore, some students at the same school yet in different classroom placements had the same teacher for math and/or language arts instruction.

Fourth, the survey did not include a thorough demographic section for teachers to complete. Teachers were only asked about the subject area they taught and were certified in, as well as their primary instructional role during the 2010-2011 school year. Therefore, no data were gathered in other areas to really get an understanding of who they were as teachers. Other demographic data that could have been gathered include number of years taught, gender, and race/ethnicity; these factors may have influenced their instructional practices for Black students with learning disabilities.

Finally, the study did not identify the model of support used for students in the inclusive placements. The course codes used to identify the placement did not make any distinction as to whether the general education placement was in a co-taught setting or if it was consultation only. This variable was not taken into consideration. It is possible that the data may have yielded different results if the analysis only included students in a particular model of support for inclusion classroom placement. 


\section{Suggestions for Future Research}

The results of this study recommend certain areas for future research. This investigation looked to establish a relationship between inclusive and resource educational placement, instructional best practices, and academic achievement. Studying other factors besides test scores would provide a better understanding of achievement and educational placement for this population of students in urban secondary settings. These factors could include grades, behavior infractions, promotions, curriculum-based assessments, and type of inclusion support model utilized. Also, future research should include data from the students' perspective as it relates to educational placement and instructional best practices. Student interviews or focus groups would provide valuable information regarding how Black students with learning disabilities at the secondary level feel about educational placement and their teachers in urban settings.

Data for this study were collected on Black students with SLD. Further research that includes data from students of other racial/ethnic backgrounds should be investigated. Examining various students, not just Blacks, with SLD in urban secondary settings would add to the research in this area.

The Teacher Instructional Practices Survey was used to collect data on instructional best practices for this study. The survey required that the teachers self-report this data. Future studies in which the use of instructional best practices was supported by classroom observations would allow for more precise data analysis. Observations of the use of the reported instructional practices would provide specific data so the research would not rely on the self-reporting of the teacher. 


\section{Chapter Summary}

This study investigated the relationship between inclusive and resource educational placement, instructional best practices, and the academic achievement of Black students with SLD in urban secondary school settings. This chapter discussed the findings of this study with a connection to relevant literature. The results implied that there is a need for professional development for both general and special education teachers on instructional best practices for SWD and that there should be certain IEP team considerations when it comes to making placement decisions for this population of students with disabilities.

Several limitations to this study were discussed, including the low return rate for teacher surveys. It was suggested that future research in this area include factors other than just test scores to measure achievement and that students of other races/ethnicities who have SLD be included in such studies. Also, it was recommended that student perspectives be included and that data collected on instructional best practices include classroom observations for a more detailed data analysis when examining educational placement, instructional best practices, and achievement of Black students with disabilities. 


\section{REFERENCES}

Access Center. (n.d.). Teaching matters: The link between access to the general education curriculum and performance on state assessments. Retrieved from www.k8accesscenter.org

Anderson, S., Yilmaz, O., \& Washburn-Moses, L. (2004). Middle and high school students with learning disabilities: Practical academic interventions for general education teachers-A review of the literature. American Secondary Education, $32(2), 19-38$.

Artiles, A. J., \& Trent, S. C. (1994). Overrepresentation of minority students in special education: A continuing debate. Journal of Special Education, 27(4), 410-437.

Berry, R. Q., III (2003). Mathematics standards, cultural styles, and learning preferences: The plight and the promise of African American students. The Clearing House, (76) 5, 244-249.

Blanchett, W. J. (2009). A retrospective examination of urban education: From "Brown" to the resegregation of african americans in special education--it is time to "go for broke". Urban Education, 44(4), 370-388.

Blanchett, W. J., Klingner, J. K., \& Harry, B. (2009). The intersection of race, culture, language, and disability: Implications for urban education. Urban Education, 44(4), 389-409.

Blanchett, W. J., Mumford, V., \& Beachum, F. (2005). Urban school failure and disproportionality in a post-Brown era: Benign neglect of the constitutional rights of students of color. Remedial and Special Education, 26(2), 70-81.

Bogdan, R. C., \& Biklen, S. K. (2007). Qualitative research for education: An introduction to theory and methods $\left(5^{\text {th }}\right.$ ed). Boston, MA: Pearson Education, Inc.

Bost, L. W., \& Riccomini, P. J. (2006). Effective instruction: An inconspicuous strategy for dropout prevention. Remedial and Special Education, 27(5), 301-311.

Bouck, E. C. (2006). How educational placements impact classroom interactions: Experiences of six secondary students with mild mental impairment. Journal of Classroom Interaction, 41(1), 4-14.

Brayboy, B. M., Castagno, A. E., \& Maughan, E. (2007). Equality and justice for all? Examining race in educational scholarship. Review of Research in Education, 31, 159-194. 
Brosnan, F. L. (1983). Overrepresentation of low-socioeconomic minority students in special education programs in California. Learning Disability Quarterly, 6(4), $517-525$.

Byrnes, J. P. (2003). Factors predictive of mathematics achievement in White, Black, and Hispanic 12th graders. Journal of Educational Psychology, 95(2), 316-326.

Carter, E. W., Wehby, J., Hughes, C., Johnson, S. M., Plank, D. R., Barton-Arwood, S. M., \& Lunsford, L. B. (2005). Preparing adolescents with high-incidence disabilities for high-stakes testing with strategy instruction. Preventing School Failure 49(2), 55-62.

Cartledge, G., \& Kourea, L. (2008). Culturally responsive classrooms for culturally diverse students with and at risk for disabilities. Exceptional Children, 74(3), 351371.

Cawley, J., Hayden, S., Cade, E., \& Baker-Kroczynski, S. (2002). Including students with disabilities into the general education science classroom. Exceptional Children, $68(4), 423-435$.

Chamberlain, S. P. (2005). Recognizing and responding to cultural differences in the education of culturally and linguistically diverse learners. Intervention in School and Clinic, 40(4), 195-211.

Cohen, J. (1970). Statistical power analysis for the behavioral sciences. New York: Academic Press.

Cook, B. G., Tankersley, M., \& Landrum, T J. (2009). Determining evidence-based practices in special education. Exceptional Children, 75(3), 365-383.

Darling-Hammond, L. (2000). New standards and old inequalities: School reform and the education of African American students. Journal of Negro Education, 69(4), 263287.

Donovan, M. S., \& Cross, C. T. (Eds.). (2002). Minority students in special and gifted education. Washington, DC: National Academies Press.

Duchnowski, A. J., Kutash, K., Sheffield, S., \& Vaughn, B. (2006). Increasing the use of evidence-based strategies by special education teachers: A collaborative approach. Teaching \& Teacher Education: An International Journal of Research and Studies, 22(7), 838-847.

Ferri, B. A, \& Connor, D. J. (2005). Tools of exclusion: Race, disability, and (re)segregated education. Teachers College Record, 107(3), 453-474. 
Florida Department of Education (2000). Least restrictive environment considerations related to individual educational plans. Technical assistance paper. Retrieved from http://www.firn.edu/doe/commhome/toc-index.htm

Florida Department of Education (2009). Understanding FCAT reports 2009. Retrieved from http://fcat.fldoe.org/pdf/ufr_2009.pdf

Florida Department of Education (2011a). 2011 LEA profile. Tallahassee, FL.

Florida Department of Education (2011b). Adequate yearly progress (AYP) reportDistrict level. Retrieved from http://schoolgrades.fldoe.org/default.asp

Ford, D. Y. \& Kea, C. D. (2009). Creating culturally responsive instruction: For students' and teachers' sakes. Focus on Exceptional Children, 41(9), 1-16.

Fore, C., III, Hagan-Burke, S., Burke, M. D., Boon, R. T., \& Smith, S. (2008). Academic achievement and class placement in high school: Do students with learning disabilities achieve more in one class placement than another? Education and Treatment of Children, 31(1), 55-72.

Fuller, E. J., \& Johnson, J. F., Jr. (2001). Can state accountability systems drive improvements in school performance for children of color and children from lowincome homes? Education and Urban Society, 33(3), 260-283.

Gay, G. (2002a). Culturally responsive teaching in special education for ethnically diverse students: Setting the stage. Qualitative Studies in Education, 15(6), 613629.

Gay, G. (2002b). Preparing for culturally responsive teaching. Journal of Teacher Education, 53(2), 106-116.

Gay, G. (2004). Beyond brown: Promoting equality through multicultural education. Journal of Curriculum and Supervision, 19(3), 193-216.

Green, S. B. (1991). How many subjects does it take to do a regression analysis? Multivariate Behavioral Research, 26, 449-510.

Gordon, R., Piana, L. D., \& Keleher, T. (2000). Facing the consequences: An examination of racial discrimination in U.S. public schools. The Applied Research Center. Retrieved from http://www.arc.org

Hagan-Burke, S., \& Jefferson, G. L. (2002). Using data to promote academic benefit for included students with mild disabilities. Preventing School Failure, 46(3), 112118. 
Handler, B. R. (2003, April). Special education practices: An evaluation of educational environmental placement trends since the regular education initiative. Paper presented at the Annual Meeting of the American Educational Research Association, Chicago, IL. Retrieved from http://vnweb.hwwilsonweb.com.ezproxy.fiu.edu/hww/results/external_link_mainc ontentframe.jhtml?_DARGS=/hww/results/results_common.jhtml.44

Hanushek, E. A., \& Raymond, M. E. (2005). Does school accountability lead to improved student performance? Journal of Policy Analysis and Management, 24(2), 297-327.

Harry, B., \& Klingner, J. (2006). Why are so many minority students in special education? Understanding race \& disability in schools. New York, NY: Teachers College Press.

Hart, J. E. (2009). Strategies for culturally and linguistically diverse students with special needs. Preventing School Failure, 53(3), 197-206.

Hayes, M. J., \& Price, V. (2000, November). Curriculum reform to address multicultural issues in special education. Paper presented at the Annual meeting of the MidSouth Educational Research Association, Bowling Green, KY.

Hinkle, D. E., Wiersma, W., \& Jurs, S. G. (2003). Applied statistics for the behavioral sciences $\left(5^{\text {th }} \mathrm{ed}\right)$. Boston, MA: Houghton Mifflin.

Howard, T. C. (2001). Telling their side of the story: African-American students' perceptions of culturally relevant teaching. Urban Review, 33(2), 131-149.

Howard, T. C. (2003). Culturally relevant pedagogy: Ingredients for critical teacher reflection. Theory into Practice, 42(3), 195-202.

Hughes, C. A, Maccini, P., \& Gagnon, J. C. (2003). Interventions that positively impact the performance of students with learning disabilities in secondary general education classes. Learning Disabilities, 12(3), 101-111.

Individuals with Disabilities Education Improvement Act of 2004. 20 USC 1400 note.

Karger, J. (2004). Access to the general curriculum for students with disabilities: The role of the IEP. Wakefield, MA: National Center on Accessing the General Curriculum. Retrieved from http://www.cast.org/publications/ncac/ncac_iep.html

Karger, J. (2005). Access to the general education curriculum for students with disabilities: A discussion of the interrelationship between IDEA '04 and NCLB. Wakefield, MA: National Center on Accessing the General Curriculum. Retrieved from http://www.cast.org/publications/ncac/ncac_discussion2004. html 
Karger, J., \& Hitchcock, C. (2003) Access to the general curriculum for students with disabilities: A brief for parents and teachers. Wakefield, MA: National Center on Accessing the General Education Curriculum.

Kauffman, J.M. (1996). Think about these things: Gentleness, truth, justice, excellence. Education and Treatment of Children, 19(3), 218-232.

Kellow, J. T., \& Jones, B. D. (2008). The effects of stereotypes on the achievement gap: Reexamining the academic performance of African American high school students. Journal of Black Psychology, 34(1), 94-120. doi:10.1177/0095798407310537

King-Sears, M. E. (2001). Three steps for gaining access to the general education curriculum for learners with disabilities. Intervention in School and Clinic 37(2), 67-76.

Klingner, J. K., Artiles, A. J., Kozleski, E., Harry, B., Zion, S., Tate, W., Duran, G. Z., \& Riley, D. (2005). Addressing the disproportionate representation of culturally and linguistically diverse students in special education through culturally responsive educational systems. Education Policy Analysis Archives, 13(38) Retrieved from www.csa.com

Kozik, P. L., Cooney, B., Vinciguerra, S., Gradel, K., \& Black, J. (2009). Promoting inclusion in secondary schools through appreciative inquiry. American Secondary Education, 38(1), 77-91.

Kozleski, E. B., \& Smith, A. (2009). The complexities of systems change in creating equity for students with disabilities in urban schools. Urban Education, 44(4), 427451.

LeRoy, B., \& Kulik, N. (2001). The demography of inclusive education in michigan: State and local district findings Retrieved from www.csa.com

Losen, D. J., \& Orfield, G., (Eds.). (2002). Racial inequity in special education. Harvard Education Publishing Group, 8 Story Street, 5th Floor, Cambridge, MA 02138

Luster, J. N., \& Durrett, J. (2003, November). Does educational placement matter in the performance of students with disabilities? Paper presented at the Annual Meeting of MSERA, Biloxi, MS.

Maccini, P., Gagnon, J. C., \& Hughes, C. A. (2002). Technology-based practices for secondary students with learning disabilities. Learning Disability Quarterly, 25, 247261. 
Maddahian, E. (2004). Evaluation of the implementation of culturally relevant and responsive education. publication no. 218 . Retrieved from http://search.proquest.com/docview/62075858

Mayer, A. P., \& Tucker, S. K. (2010). Cultivating students of color: Strategies for ensuring high academic achievement in middle and secondary schools. Journal of School Leadership, 20, 470-490.

McMillan, J.H. \& Schumacher, S. (2001). Research in education: A conceptual introduction $\left(5^{\text {th }}\right.$ ed.). New York: Addison Wesley Longman.

McNeil, K. A., Newman, I., \& Kelly, F. J. (1996). Testing research hypotheses with the general linear model. Carbondale, IL: Southern Illinois University Press.

Nagle, K., Yunker, C., \& Malmgren, K. W. (2006). Students with disabilities an accountability reform: Challenges identified at the state and local levels. Journal of Disability Policy Studies. 17(1), 28-39.

National Association for Bilingual Education (NABE) \& ILIAD Project (2002). Determining appropriate referrals of English language learners to special education: A self-assessment guide for principals. Washington, DC \& Arlington, VA: National Association for Bilingual Education and Council for Exceptional Children.

Newman, I., Fraas, J., \& Laux, J. (2000). A three-step adjustment procedure for type I error rates. Journal of Research in Education, 10(1), 84-90.

Newman, I., \& McNeil, (1998). Conducting survey research in the social sciences. Lanham, MD: University Press of America.

Newman, I., \& Newman, C. (1994). Conceptual statistics for beginners. New York: University Press of America.

Newman, I., Newman, C., Brown, R., \& McNeely, S. (2006). Conceptual Statistics for Beginners $\left(2^{\text {nd }}\right.$ ed.). Lanham, MD: University Press of America.

Newman, L. (2006). Facts from NLTS2: General education participation and academic performance of students with learning disabilities. Menlo Park, CA: SRI International. Retrieved from www.nlts2.org/fact_sheets/nlts2_fact_sheet_2006_07.pdf

No Child Left Behind Act of 2001. (2002). Pub. L. 107-110, 115 Stat. 1425. 
Nolet, V., \& McLaughlin, M. J. (2000). Accessing the general curriculum: Including students with disabilities in standards-based reform. Thousand Oaks, CA: Corwin Press, Inc.

Obiakor, F. E., \& Ford, B. A. (2002). Creating successful learning environments for African American learners with exceptionalities. Thousand Oaks, CA: Corwin Press.

Obiakor, F. E., \& Utley, C. A. (2004). Educating culturally diverse learners with exceptionalities: A critical analysis of the Brown case. Peabody Journal of Education, 79(2), 141-156.

Patton, J. M. (1998). The disproportionate representation of African-Americans in special education: Looking behind the curtain for understanding and solutions. Journal of Special Education, 32(1), 25-31.

Peterson, P. E., \& West, M. R. (2006). Is your child's school effective? Don't rely on NCLB to tell you. Education Next, 6(4), 76-80.

Planty, M., Hussar, W., Snyder, T., Kena, G., KewalRamani, A., Kemp, J., Bianco, K., \& Dinkes, R. (2009). The Condition of Education 2009 (NCES 2009-081).

Washington, DC: National Center for Education Statistics, Institute of Education Sciences, U.S. Department of Education.

Pressley, M., Raphael, L., \& Gallagher, J. D. (2004). Providence-St. Mel school: How a school that works for African American students works. Journal of Educational Psychology, 96(2), 216-235.

Rea, P. J., McLaughlin, V. L., \& Walther-Thomas, C. (2002). Outcomes for students with learning disabilities in inclusive and pullout programs. Exceptional Children, 68(2), 203-222.

Reid, D. K., \& Knight, M. G. (2006). Disability justifies exclusion of minority students: A critical history grounded in disability studies. Educational Researcher, 35(6), $18-23$.

Ross, M. C., Seaborn, A. W., \& Wilson, E. K. (2002). Is cooperative learning a valuable instructional method for teaching social studies to urban African American students? Retrieved from http://www.csa.com

Rueda, R., Gallego, M. A., \& Moll, L. C. (2000). The least restrictive environment: A place or a context? Remedial and Special Education, 21(2), 70-78. 
Santa, C. M., Havens, L. T., \& Valdes, B. J. (2007). Project CRISS creating independence through student-owned strategies $\left(3^{\text {rd }}\right.$ ed). Dubuque, IA: Kendall/Hunt.

Santamaria, L. J. (2009). Culturally responsive differentiated instruction: Narrowing gaps between best pedagogical practices benefiting all learners. Teachers College Record, 111(1), 214-247.

Schumaker, J. B., Deshler, D. D., Lenz, B. K., Bulgren, J. A., Davis, B., Grossen, B., \& Marquis, J. (2002). The educational context and outcomes for high school students with disabilities: Overview of the study and findings (Report No. RR-1). Lawrence, KS: Institute for Academic Press.

Scruggs, T. E., Mastropieri, M. A., Berkeley, S., \& Graetz, J. E. (2010), Do special education interventions improve learning of secondary content? A meta-analysis. Remedial and Special Education 31(6), 437-449.

Sheppard, P. (2006). Successful African-American mathematics students in academically unacceptable high schools. Education, 126(4), 609-625.

Skiba, R. J., Poloni-Staudinger, L., Gallini, S., Simmons, A. B., \& Feggins-Azziz, R. (2006). Disparate access: The disproportionality of African American students with disabilities across educational environments. Exceptional Children, 72(4), 411-424.

Skiba, R. J., Simmons, A. B., Ritter, S., Gibb, A. C., Rausch, M. K., Cuadrado, J., \& Chung, C. (2008). Achieving equity in special education: History, status, and current challenges. Exceptional Children, 74(3), 264-288.

Slate, J. R., \& Jones, C. H. (2006). African-American students' performance and secondary school size in the state of Texas. Essays in Education, 16, 90-105.

Soukup, J. H., Wehmeyer, M. L., Bashinski, S. M., \& Bovaird, J. A. (2007). Classroom variables and access to the general curriculum for students with disabilities. Exceptional Children, 74(1), 101-120.

Stewart, E. B. (2007). Individual and school structural effects on African American high school students' academic achievement. High School Journal, 91(2), 16-34.

Townsend, B. L. (2002). "Testing while Black": Standards-based school reform and African American learners. Remedial and Special Education, 23(4), 222-230.

U.S. Department of Education (2005). Twenty-seventh annual report to Congress on the implementation of the Individuals with Disabilities Education Act. Section 664(d) of the Individuals with Disabilities Education Act (IDEA). Washington, DC: Author. 
Villegas, A. M., \& Lucas, T. (2002). Preparing culturally responsive teachers: Rethinking the curriculum. Journal of Teacher Education, 53(1), 20-32.

Voltz, D. L., Brazil, N., \& Scott, R. (2003). Professional development for culturally responsive instruction: A promising practice for addressing the disproportionate representation of students of color in special education. Teacher Education and Special Education, 26(1), 63-73.

Wehmeyer, M. L., Lattin, D. L., Lapp-Rincker, G., \& Agran, M. (2003). Access to the general curriculum of middle school students with mental retardation: An observational study. Remedial and Special Education, 24(5), 262-272.

Wolgemuth, J. R., Cobb, R. B., \& Alwell, M. (2008). The effects of mnemonic interventions on academic outcomes fo $\mathrm{r}$ youth with disabilities: A systematic review. Learning Disabilities Research, 23(1), 1-10.

Yell, M. L., \& Katsiyannis, A. (2004). Placing students with disabilities in inclusive settings: Legal guidelines and preferred practices. Preventing School Failure, $49(1), 28-35$.

Zigmond, N. (2003). Where should students with disabilities receive special education services? Is one place better than another? Journal of Special Education, 37(3), 193-199. 


\section{APPENDIX A}

\section{Teacher Instructional Practices Survey}

The purpose of this survey is to obtain data on the instructional practices of secondary general and special education teachers during the current 2010-2011 school year. There are no right or wrong answers to any of the questions and your complete honesty will provide essential insight into classroom practices used at the middle school level. Your participation is voluntary; you and your responses will remain anonymous. Thank you for your participation.

\section{PART I:}

1. Please indicate the subject area(s) you taught during the 2010-2011 school year:

Language Arts

Math

Other

2. What subject area(s) were you certified in during the 2010-2011 school year?

3. Please indicate your primary instructional role during the 2010-2011 school year:

General Educator

Special Educator

\section{PART II:}

As it relates to the 2010-2011 school year, place an " $\boldsymbol{X}$ " next to the word that represents your agreement with each statement below.

4. I use graphic organizers to teach concepts.

_ Never _ Rarely __ Frequently__ Daily

Describe/provide example(s):

5. My students use hands-on activities more than text-based learning.

Never

Rarely

Frequently

Daily

Describe/provide example(s): 
6. I use mnemonic strategies/cues to link new information to current knowledge (i.e. keywords, etc.).

_ Never __ Rarely __ Frequently __ Daily

Describe/provide example(s):

7. Students are used to re-teach concepts to their peers.
Never
Rarely
Frequently
Daily

Describe/provide example(s):

8. I activate student background knowledge before introducing a new concept.

_ Never _ Rarely

_ Frequently Daily

Describe/provide example(s):

9. I provide guided notes to students for class lectures/discussions.

_ Never __ Rarely __ Frequently__ Daily

Describe/provide example(s):

10. I use visual displays to reinforce learning.

_ Never__ Rarely__ Frequently__ Daily

Describe/provide example(s): 
11. I use peer tutoring groups during the instructional block.

_ Never__ Rarely___ Frequently__ Daily

Describe/provide example(s):

12. Prior to moving on to a new standard/concept, I find out what students already know about the topic.

_ Never _ Rarely __ Frequently _ _ Daily

Describe/provide example(s):

13. I teach students the strategy they need to know to complete a given academic task.

Never __ Rarely

Frequently

Daily

Describe/provide example(s):

14. My instruction is highly organized and task oriented.

Never

_ Rarely

Frequently

Daily

Describe/provide example(s):

15. I use acronyms to help students remember key concepts.

_ Never _ Rarely _ Frequently_ D Daily

Describe/provide example(s): 
16. My students learn and apply concepts through activity-based assignments.

_ Never __ Rarely __ Frequently _ _ Daily

Describe/provide example(s):

17. I use advance organizers with students to focus their attention on critical information.

_ Never _ Rarely _ Frequently _ Daily

Describe/provide example(s):

18. I teach test-taking strategies/skills to my students.

_ Never__ Rarely__ Frequently __ Daily

Describe/provide example(s):

19. I present the curriculum content in a clear, systematic (logical) way.

_ Never __ Rarely __ Frequently __ Daily

Describe/provide example(s):

20. I use video and/or computer-based instructional tools for learning.

_ Never __ Rarely__ Frequently__ Daily

Describe/provide example(s): 
21. I integrate technology based lessons into the curriculum.

Never _ Rarely___ Frequently__ Daily

Describe/provide example(s):

22. I teach with the cultural background of my students in mind.

_ Never _ Rarely _ Frequently _ Daily

Describe/provide example(s):

23. I incorporate student interests into my lessons.

_ Never __ Rarely __ Frequently__ Daily

Describe/provide example(s):

PART III: Please complete the following questions to provide the researcher with a better understanding of the instructional practices you used during the 2010-2011 school year.

24. List any additional instructional practices/strategies you implemented and indicate how often you used them.

a. Describe instructional practice/strategy:

How often?

b. Describe instructional practice/strategy:

How often? 
25. Describe, in detail, what you believe to be the most effective instructional strategy/practice for students with disabilities in your subject area(s) and why.

26. Is there anything else you would like to add about the instructional practices you used during the 2010-2011 school year? 


\section{APPENDIX B}

Variables

\begin{tabular}{|c|c|}
\hline Code & Scale \\
\hline Student Educational Placement (EPL) & $\begin{array}{l}0=\text { Inclusive }(\mathrm{IN}) \\
1=\text { Resource }(\mathrm{RE})\end{array}$ \\
\hline \multicolumn{2}{|l|}{ Student Achievement Gains } \\
\hline Pre Reading Score (PreRDG) & Scale (100-500) \\
\hline Post Reading Score (PosRDG) & Scale $(100-500)$ \\
\hline Achievement Gains in Reading (AGR) & $\begin{array}{l}\text { Actual number } \\
\text { (PosRDG minus PreRDG) }\end{array}$ \\
\hline Pre Math Score (PreMTH) & Scale $(100-500)$ \\
\hline Post Math Score (PosMTH) & Scale (100-500) \\
\hline Achievement Gains in Math (AGM) & $\begin{array}{l}\text { Actual number } \\
\text { (PosMTH minus PreMTH) }\end{array}$ \\
\hline Student Gender (GEN) & $\begin{array}{l}0=\text { Male } \\
1=\text { Female }\end{array}$ \\
\hline \multicolumn{2}{|l|}{ Instructional Best Practices } \\
\hline Graphic Organizers (GO) & Scale (1-4) \\
\hline Mnemonic Strategies (MS) & Scale (1-4) \\
\hline Peer-Mediated Activities (PMA) & Scale $(1-4)$ \\
\hline Study Aids (SA) & Scale $(1-4)$ \\
\hline Activating Knowledge (AK) & Scale (1-4) \\
\hline Activity-Based Learning (ABL) & Scale $(1-4)$ \\
\hline Strategy Instruction (SI) & Scale (1-4) \\
\hline Explicit Instruction (EI) & Scale (1-4) \\
\hline Technology-Based Practices (TBP) & Scale $(1-4)$ \\
\hline Culturally Responsive Teaching (CRT) & Scale (1-4) \\
\hline
\end{tabular}


VITA

\section{DEIDRE MARSHALL PHILLIPS}

Born, Atlanta, Georgia

$1995-2000$

B.A., Emotional Disturbances and Learning Disabilities Florida State University

Tallahassee, Florida

M.S., Emotional Disturbances and Learning Disabilities Florida State University

Tallahassee, Florida

Adjunct Instructor

Florida International University

Miami, Florida

$2009-2012$

Doctoral Candidate

Florida International University

Miami, Florida

\section{PUBLICATIONS AND PRESENTATIONS}

Cramer, E.D., Salazar, M., \& Marshall, D. (2008) Urban inclusive practices: A mixed methodological examination. National Journal of Urban Education and Practice, 1(4), 385-397.

Nevin, A., Cohen, J., Salazar, L., \& Marshall, D. (February, 2007). Student Teacher Perspectives on Inclusive Education. Paper presented at refereed conference of American Association of Colleges of Teacher Education, New York, New York. 